\title{
Exchange market pressure in South Africa and Kenya: An analysis using parametric and non-parametric extreme value theory
}

\begin{tabular}{|c|c|}
\hline \multicolumn{2}{|c|}{$\begin{array}{l}\text { Authors: } \\
\text { Pieter-Henk Boer }{ }^{1} \\
\text { Elias Munapo }{ }^{2} \\
\text { Martin Chanza } \\
\text { Issaah A. Mhlanga }\end{array}$} \\
\hline \multicolumn{2}{|c|}{$\begin{array}{l}\text { Affiliations: } \\
{ }^{1} \text { Department of Human } \\
\text { Movement Science, Cape } \\
\text { Peninsula University of } \\
\text { Technology, Wellington, } \\
\text { South Africa }\end{array}$} \\
\hline \multicolumn{2}{|c|}{$\begin{array}{l}\text { 2Department of Business } \\
\text { Statistics and Operational } \\
\text { Research, North-West } \\
\text { University, Mahikeng, } \\
\text { South Africa }\end{array}$} \\
\hline \multicolumn{2}{|c|}{$\begin{array}{l}{ }^{3} \text { Alexander Forbes Investment, } \\
\text { Santon, South Africa }\end{array}$} \\
\hline \multicolumn{2}{|c|}{$\begin{array}{l}\text { Corresponding author: } \\
\text { Pieter-Henk Boer, } \\
\text { boerp011@gmail.com }\end{array}$} \\
\hline \multicolumn{2}{|c|}{$\begin{array}{l}\text { Received: } 23 \text { Mar. } 2018 \\
\text { Accepted: } 26 \text { Nov. } 2018 \\
\text { Published: } 29 \text { Apr. } 2019\end{array}$} \\
\hline \multicolumn{2}{|c|}{$\begin{array}{l}\text { How to cite this article: } \\
\text { Boer, P-H., Munapo, E, } \\
\text { Chanza, M. \& Mhlanga, I.A., } \\
\text { 2019, 'Exchange market } \\
\text { pressure in South Africa and } \\
\text { Kenya: An analysis using } \\
\text { parametric and non- } \\
\text { parametric extreme value } \\
\text { theory', Journal of Economic } \\
\text { and Financial Sciences 12(1), } \\
\text { a202. https://doi.org/ } \\
\text { 10.4102/jef.v12i1.202 }\end{array}$} \\
\hline \multicolumn{2}{|c|}{$\begin{array}{l}\text { Copyright: } \\
\text { (c) 2019. The Authors. } \\
\text { Licensee: AOSIS. This work } \\
\text { is licensed under the } \\
\text { Creative Commons } \\
\text { Attribution License. }\end{array}$} \\
\hline \multirow[b]{2}{*}{ 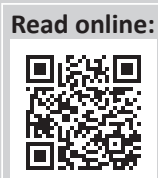 } & \\
\hline & $\begin{array}{l}\text { Scan this QR } \\
\text { code with your } \\
\text { smart phone or } \\
\text { mobile device } \\
\text { to read online. }\end{array}$ \\
\hline
\end{tabular}

Orientation: Exchange market pressure (EMP) is the selling pressure of domestic currency or excess demand needed for foreign currency.

Research purpose: The purpose of this study was to analyse EMP using extreme value theory (EVT) and to compare two commonly used EVT methods.

Motivation for the study: To determine whether the EMP of two African countries can be modelled with EVT, and if so, which method would be best suited. To determine periods of extreme pressure or currency crisis by using these methods. Lastly, to study the individual components of the EMP index during these periods of stress of crises.

Research design/approach and method: The monthly data of the three components of the EMP index for two African countries (Republic of South Africa [RSA] and Kenya) were studied for a period of 19 years (1999-2017). The data were modelled using the generalised Pareto distribution (GPD) with the peak over threshold (POT) method using maximum likelihood estimation. Moreover, the data were also modelled using the non-parametric Hill estimate. Appropriate estimated and empirical quantiles are reported in order to determine periods of extreme pressure or crises. The components of the EMP RSA data set were modelled with appropriate autoregressive moving averages and/or autoregressive conditional heteroscedasticity/generalised autoregressive conditional heteroscedasticity (ARMA/ $\mathrm{ARCH} / \mathrm{GARCH}$ ) processes to ensure independent and identically distributed variables.

Main findings: Reliable and accurate estimates were obtained for the scale and shape parameter using the GPD POT method for both countries. Positive shape parameters confirmed generalised extreme value distributions with heavy tails of the Frechet type. Similarly, accurate and reliable shape estimates were computed using the non-parametric Hill estimator for both countries.

Practical/managerial implications: The GPD POT method more closely reflected estimates to the empirical qauntiles compared to the Hill method. It is feasible to model the EMP data of two African countries with EVT using both POT estimation methods. However, the GPD method using maximum likelihood estimation was more accurate compared to the nonparametric Hill estimate.

Contribution/value-add: It is feasible to model the EMP data of two African countries using EVT using both POT methods. As a consequence periods of extreme pressure could be identified. Therefore the individual components of the EMP at those periods of extreme pressure could be studied more closely.

Keywords: exchange market pressure; extreme value theory; generalised Pareto distribution; peak over threshold; Hill estimate; extreme pressure; currency crisis.

\section{Introduction}

Exchange market pressure (EMP) was introduced and developed by the pioneering researchers Girton and Roper in 1977. Changes in the exchange rate exert an influence on a given country's macroeconomic management, which affects indices such as inflation, trade balance, unemployment and many others. The exchange rate could be pressurised because of the selling pressure of the domestic currency or excess demand for foreign currency. The monetary authority of the country can either intervene or allow the pressure to appreciate or depreciate the exchange rate. If intervention is implemented in periods of depreciative pressure, the policymakers usually raise the interest rate to attract investment opportunities or sell international reserves to meet the 
demand of foreign currency (Guru \& Sarma 2013). To encapsulate currency exchange pressure, an understanding and analysis of exchange rate depreciation, decreases in foreign exchange reserves and increases in interest rate is fundamental. To include these three essential forms of pressure into a single composite factor or index is what is known as EMP. The objective of EMP is to determine periods of 'extreme pressure' or currency crises (two or more continuous periods of stress) (Guru \& Sarma 2013). A simplistic definition of currency crisis would be large movements in the nominal exchange rates (Pozo \& AmuedoDorantes 2003). Other macroeconomic variables, such as disproportionate credit growth, over-appraisal of exchange rate, a decline in international reserves, rising interest rates, an increase in the current account deficit, outflow of portfolio management and flight of capital are a few predictors of extreme pressure or currency crisis (Guru \& Sarma 2013; Heinz \& Rusinova 2015; McFarlane 2010; Pozo \& AmuedoDorantes 2003).

Positive changes in the EMP index reflect depreciative changes, thus reflecting stronger selling pressure of the domestic currency or excess demand for foreign currency. It is important to note that negative values of the EMP index reflect the appreciative nature of the exchange index and do not imply depreciative pressure. Examples are increases in reserves or decreases in the interest rate. Consequently, the values of the right (upper depreciative tail) will be studied. For many years it has been reported that financial data rarely fit a normal distribution; in fact, most financial data are heavy tailed and leptokurtic (Fama 1965).

Extreme value theory (EVT) is a special branch of probability theory adapted to extremal analysis. It deals with the asymptotic behaviour of tail observations (Rocco 2014). The probability of extreme events under heavy-tailed distributions will be underestimated if two or three standard deviations from the mean are used as in the normal distribution (Eichengreen, Rose \& Wyplosz 1995; Kaminsky \& Reinhart 1998; McFarlane 2010). Pozo and AmuedoDorantes (2003) reported that the extreme value method indicated not only more evidence of speculative pressure but also accurate indications of crisis incidences. Even when the tails of distribution are thin, the extreme value method provides results similar to a normal distribution (Pozo \& Amuedo-Dorantes 2003). Recognising the limitations of crisis-based threshold (two- or three- $\sigma$ ), recent literature has focussed on the extreme value approach (Cumperayot \& Kouwenberg 2013; Pozo \& Amuedo-Dorantes 2003). The extremal types theorem (Fisher-Tippett theorem) stipulates that if the extreme observation converges in distribution to a non-degenerate probability distribution, then it belongs to one of three families: thin-tailed (Gumbel), fat-tailed (Frechet) or no-tail (Weibull). The three families can be combined together and is known as the generalised extreme value. The sign of the parameter of the generalised extreme value can be positive (Frechet such as student's T or Pareto), zero (Gumbel such as normal or exponential) or negative (no tail such as Weibull and Beta distribution). A large body of literature providing a detailed account of EVT and applications thereof is available (Beirlant, Goegebeur \& Teugels 2004; Coles 2013; Embrechts, Kluppelberg \& Mikosch 2013; McNeil, Frey \& Embrechts 2005; Reiss \& Thomas 2013).

Another non-parametric technique for estimating the tail index of extreme values is known as the Hill estimate (Hill 1975). Most studies thus far have used this technique to estimate the tail index (McFarlane 2010). The distribution of the data is required to be from a fat-tailed (Frechet) distribution (Hill 1975; Huisman et al. 2001; Koedijk \& Kool 1992; McFarlane 2010). An advantage of this technique is that it has been reported to be an unbiased estimator of small sample sizes.

However, recent papers have used another extreme value technique recognised as the peaks over threshold (POT) for estimating the tail index (Guru \& Sarma 2013). This method is preferred as it is applicable to fat-tailed, thin-tailed and notailed distributions. Moreover, the tail of the EMP index distribution can be estimated by fitting a generalised Pareto distribution (GPD) to values beyond a certain threshold. The POT method is formulated from the Pickland-Balkema-De Haan theorem which uses values more than a particular threshold to be approximated by the GPD. However, the underlying distribution must meet the Fisher-Tippett theorem. This approach enables the researcher to identify extreme observations without making assumptions regarding the value of the unknown distribution shape parameter. This method is advantageous over the $\sigma$-based method (where the distribution is assumed to be normal) or the Hill estimation that is based on non-parametric techniques and only relevant to a fat-tailed distribution.

When implementing the POT method, a threshold $\mu$ must be identified to define the beginning of the tail. Then a GPD is fitted to the peaks over the threshold $\mu$ by implementing maximum likelihood estimation. When the GPD parameters are estimated for the 'surpassing' values, the $p$ th quantile on the tail of the distribution can be estimated. Usually, when using the POT approach, one would implement the probability stress threshold fixed at 0.05 (95th percentile) or at 0.01 (99th percentile). Using this formula, the entire tail region can be calculated by different probability quantiles (Guru \& Sarma 2013)

When choosing the value for the tail threshold, $\mu$, there is a balance trade-off between variance and bias. If the value chosen is too high, there would be few observations resulting in high variability. If the value chosen is too low, the tail region of the distribution may be biased (McNeil \& Frey 2000). Recent research has opted to use the top $20 \%$ of values if observations are taken from 20 years of data (Guru \& Sarma 2013). If the sample is small, the non-parametric Hill estimation method may be more suitable. 
To the researcher's knowledge, research examining EMP using EVT has never been conducted in Africa. A few studies have studied EMP in Africa but have never gone so far to model the data using EVT (De Macedo, Pereira \& Reiss 2009; Fiador \& Biekpe 2015). An analysis of this kind is especially important in developing countries where negative net export positions arise, with a deteriorating foreign exchange position. Moreover, in developing countries, variables such as the output growth (lower gross domestic product [GDP] implies smaller demand for money), private capital flows (capital inflows end up in the consumption market), current account balance (inverse relationship with EMP), terms of trade (deteriorating terms of trade imply a need for more foreign currency) and public debt are usually different from that of developed countries.

Also, most studies in other regions did not employ EVT. The EMP has not been compared using the Hill estimate and GPD in EVT. We do not know whether these methods will be feasible in an African context and, if so, whether EMP would be estimated accurately. Moreover, during the past 20 years, periods of high and lower volatility regarding EMP pressure can be identified, as well as the relative contribution of each factor involved with the EMP, that is, changes in the exchange rate or changes in foreign reserves or changes in the interest rate. An in-depth analysis could help identify possible causes of the relative contributions of each factor.

Therefore, the research questions that arise from this study are the following: is it possible to model the data using EVT? Which estimation method (Hill or GPD POT) is best to accurately estimate periods of extreme pressure? Finally, what are the individual contributions for the three factors involved with EMP estimation in periods of stress or crisis? Consequently, the purpose of the study is fourfold:

- to determine whether the EMP index of two African countries is stationary and heavy-tailed or not, and if so, to model the data using EVT

- to compare the parametric (GPD POT) and nonparametric (Hill) estimation methods in describing periods of extreme pressure in South Africa and Kenya

- to identify periods of extreme pressure or crises in South Africa and Kenya using extremal analysis for the period 1999-2017

- to study the three components of EMP estimation at periods of extreme pressure or crisis.

\section{Research methodology}

Financial data from various African countries from 1999 to 2017 were obtained from the Global Markets Research team from one of the leading banks in South Africa. Data from South Africa and Kenya were the most complete for the longest period in time and were thus considered best for analysis.

\section{Research design}

This study was quantitative and exploratory in nature, where financial data for two different African countries (SA and Kenya) for the past 20 years were analysed to construct a monthly EMP index. Quantitative and exploratory research methods were used to employ statistical and mathematical models pertaining to EMP.

\section{Data analysis}

\section{Exchange rate, interest rate and reserves-to-M1 money supply}

The data obtained included monthly data pertaining to the average monthly exchange rate of the South African Rand (ZAR) and the Kenyan shilling against the US dollar. Also, the ratio of monthly reserves to base values (indicative of the adequacy of reserves and how much the foreign exchange reserves cover the most liquid money supply) was obtained for each country. Lastly, data for the movement of monthly nominal interest rates were obtained. The movements of these three components and their relative changes are schematically demonstrated in the results section. All three variables were computed to reflect rate relative changes. All three financial variables (rate-of-change in exchange rate, rate-of-change in interest rate and rate-ofchange in reserves-to-M1) must demonstrate stationarity if used for subsequent analysis with EVT. Other than the general descriptive statistics (mean, median, variance, standard deviation, skewness and kurtosis), the stationarity according to the Jarque-Bera test statistic was determined as a first step. Another important component when applying EVT is the assumption of no-autocorrelation in the time series. The next section explains how the data analysis was applied in such instances.

\section{Autoregressive conditional heteroscedasticity/generalised autoregressive conditional heteroscedasticity processes}

The second step towards achieving an EMP index was to specify the time series dynamics of each of the components. When no time-varying volatilities were observed, the appropriate standard deviations were used for components that display features of conditional heteroscedasticity using autoregressive conditional heteroscedasticity (ARCH) and generalised autoregressive conditional heteroscedasticity (GARCH) models. The standard Box-Jenkins methodology was applied to arrive at the best fitting time series model. In doing so, the EMP series was standardised for each individual component if serial correlation was reported to achieve independence and identically distributed (iid) distribution. The results of the Box-Jenkins methodology and Ljung Box Q-statistics for the first and second moments are demonstrated in tables for the three components (see the results section). The basic statistics of exchange rate, nominal interest rate and ratio of reserves to base money are presented in a table (Table 1) in the results section (maximum, minimum, mean, standard deviation, variance, skewness and kurtosis). Possible periods of more and less volatility are identified within the total period of 19 years (SA) and 18 years (Kenya). 
TABLE 1: South African descriptive statistics and time series tests of components of exchange market pressure.

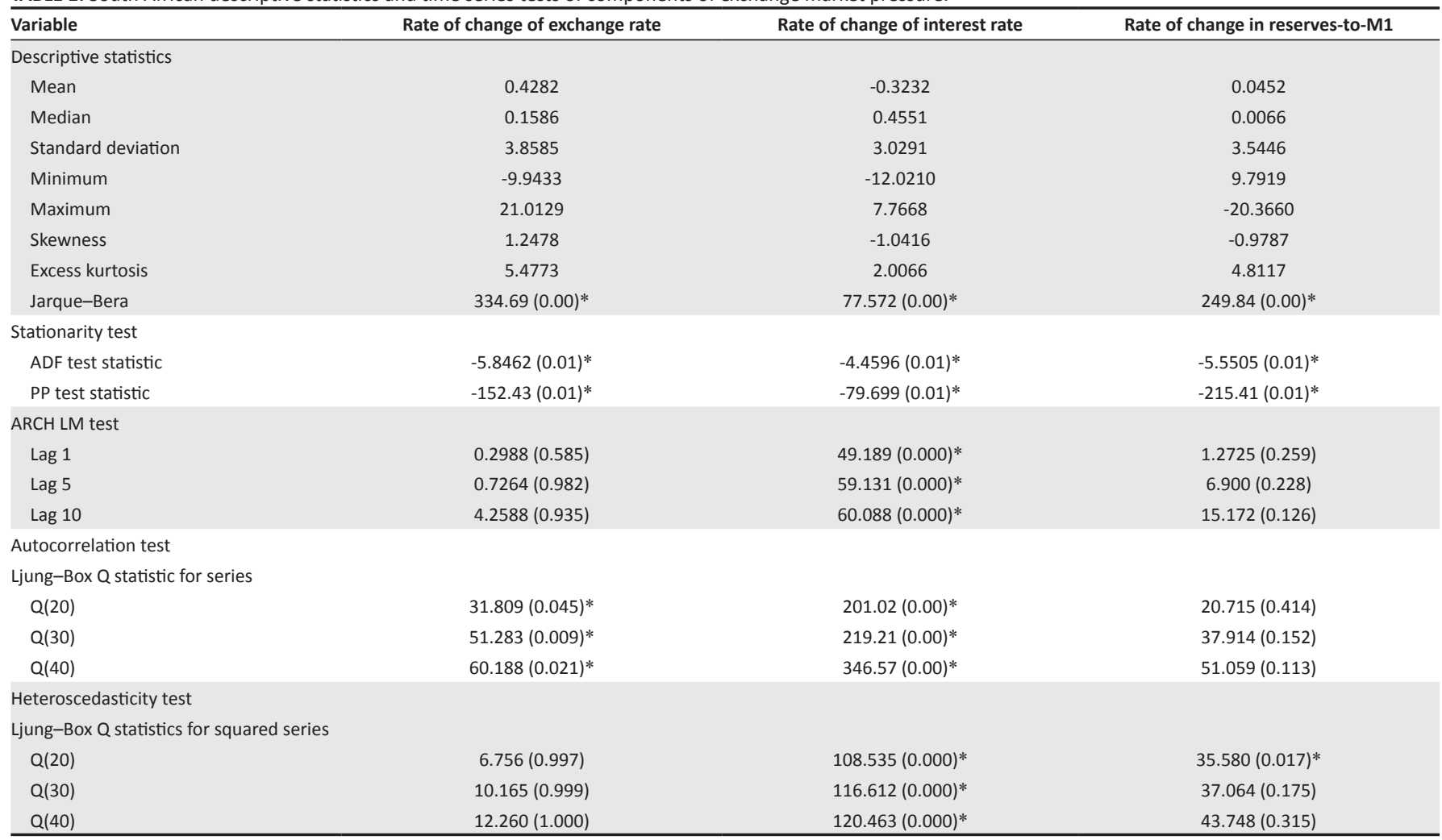

Source: Guru, A. \& Sarma, M, 2013, Exchange market pressure in India, Discussion Papers in Economics 15, pp. 22-45

ADF,Augmented Dickey-Fuller test; PP, Phillips-Perron test; ARCH, auto regressive conditional heteroscedasticity; LM, Lagrange Multiplier.

$*$, values significantly less than 0.05 .

\section{Calculation of the exchange market pressure index}

The EMP index was calculated according to the model independent approach as outlined by Eichengreen, Rose and Wyplosz (1994) and Eichengreen et al. (1995).

$$
E M P_{t}=e_{t}-\left[\sigma_{e} / \sigma_{r}\right] r_{t}+\left[\sigma_{e} / \sigma_{i}\right] i_{t}
$$

where $e_{t}$ is the relative change in nominal exchange rate of ZAR against US dollar in month $t ; r_{t}$ is the relative change in ratio of gross forex reserves to narrow money (reservesto-M1) in month $t ; i_{t}$ is the relative change in interest rate in month $t ; \sigma_{e^{\prime}} \sigma_{r^{\prime}}$ and $\sigma_{i}$ are the standard deviations of $e_{t^{\prime}} r_{t}$ and $i_{t,}$ respectively.

The descriptive statistics, tests for normality, skewness, kurtosis and autocorrelation, were analysed with statistical package $\mathrm{R}$ and RStudio (CRAN, R Core Team 2016). The website for the $R$ project is http://www.r-project.org and the source code is http://www.gnu.org/licences/gpl. $\mathrm{html}$. The $\mathrm{R}$ language is a dialect code of the $\mathrm{S}$ language, which was formulated by John Chambers at the Bell Labs in the 1970s.

\section{Defining market stress using extreme value theory}

In this study, extreme positive values of the EMP index as indicative of intense currency market pressure were examined. The probability of a crisis event, that is, an EMP index, that exceeds the [(1-p) $\times 100]$ percentile will indicate a stress event. Consequently, a threshold value for the identification of a stress event is provided. Where the observed value of the EMP index is more than this threshold, the index at that particular point can be considered under stress. The quantiles of these points (usually 95th or 99th percentile) are located in the tail regions of a probability density function. Financial data often display non-normal behaviour with asymmetry and kurtosis.

Generalised Pareto distribution: Peak over threshold: The largest $20 \%$ of the EMP index values were considered extreme observations (Guru \& Sarma, 2013). A GPD was fitted to the 'excesses' over $\mu$ and applied the estimated GPD parameters to compute crisis thresholds given for the 95th and 99th percentiles. An observation of the EMP index larger than these thresholds will be indicative of a stress situation. Several tail quantiles for different probability levels $p$ were computed to compare the results of the GPD to that of a normal distribution and the empirical (actually observed) quantiles.

The GPD parameters are estimated for the 'exceeding' values and the $p$ th quantile on the tail of the distribution was estimated using the following equation proposed by McNeil and Frey (2000):

$X_{p}=\mu+\sigma / \xi\left[(n p / k)^{-\xi}-1\right]$ 
where $n$ is the total number of observations, $k$ is the number of observations above the threshold $\mu, \hat{\sigma}, \hat{\xi}$ are maximum likelihood estimates of the GPD parameters and $p$ is the probability level.

Hill estimator: The Hill estimator was also fitted to the 'threshold' values as discussed in the previous section. The Hill estimator was fitted to the tail of the distribution and the estimated Hill parameter (Xi) was used to compute crisis thresholds at the 95th and 99th percentiles. Again several tail quantiles (for different probability levels $p$ ) were computed to compare the results of the Hill estimator not only to that of the empirical quantiles but also to that of the GPD POT and normal distribution.

The data are sorted from the largest to the smallest $(X 1, n>\ldots$ $X n, n)$. The formula as proposed by Hill (1975) is given below:

$$
H k, n=k^{-1} \sum_{j=1}^{k} \log (n-j+1)-\log X_{n-k}
$$

where $K$ represents the cut-off between the tail and central observations so that $X j, n$ can be considered extreme observations.

Alternatively, this formula can also be structured in a different way that is more user-friendly (Kang \& Song 2017).

$\xi_{n}=\frac{1}{n} \sum_{i=1}^{n} \log X_{i}-\log X_{n+1}$

where $n$ represents the largest observations (cut-off between tail and central observations).

The 100pth quantile using the Hill estimator is computed by the following formula (Kang \& Song 2017):

$$
X_{p}=X_{n+1}[n+1 / N+1]^{\xi_{n}}
$$

where $n$ is the tail observations, $N$ is the entire sample and $X i$ is the Hill estimator.

\section{Analysis of the stress episodes}

Once the stress events are identified, an analysis of the stress events can be performed in the context of prevailing conditions in these countries around the stress periods. Furthermore, the contribution of each of the three components of the EMP index can be assessed during the stress periods.

\section{Statistical analysis}

All data were analysed in the statistical package R (CRAN, R Core Team 2016) and Microsoft Excel (Microsoft, Redmont, United States). Firstly, the three components of the EMP index were analysed as rate-of-changes in Microsoft Excel. Subsequently, the descriptive statistics and skewness, kurtosis, normality and stationarity were reported in $\mathrm{R}$ with the packages 'tseries' (Trapletti, Hornik \& LeBaron 2017), 'forecast' (Hyndman et al. 2017) and 'fBasics' (Wuertz,
Setz \& Chalabi 2014). The next step was to calculate the time-varying volatilities with appropriate autoregressive moving averages (ARMA) and/or ARCH/GARCH processes (for each one of the three components of the EMP index). These analyses were also conducted in $\mathrm{R}$ with the packages 'portes' (Mahdi \& McLeod 2017) and 'rugarch' (Ghalanos 2015). Ljung-Box statistics for the mean and squared series were used to identify whether ARMA and/or time-varying volatilities were present. Finally, the EMP index was calculated using Equation 1. Again, descriptive statistics in association with skewness, kurtosis, normality, stationarity and Ljung-Box statistics are provided. Subsequently, the EMP index was modelled with the GPD POT and Hill estimation methods. This analysis was performed in R with the packages 'fextremes' (Wuertz 2013), 'extRemes' (Gilleland 2016) and 'ReIns' (Reynkens et al. 2017). Estimates for the shape and scale parameters are provided. The estimates were also manually calculated in Microsoft Excel (Microsoft, Redmont, United States) using Equation 4 for certainty. Lastly, the quantile for each method was calculated for $p=0.001$ to $p=0.2$ using $\mathrm{R}$ and manual calculations (Formulas 2 and 5). The empirical quantiles were calculated manually in Microsoft Excel using the quantiles $p=0.001$ to $p=0.2$. As a final step, periods of crisis and the main contributor of the EMP index were identified. These analyses were run for two African countries, namely SA and Kenya. Probability values less than 0.05 were considered statistically significant.

\section{Ethical considerations}

Ethical approval was granted by the North-West University Ethical Committee (ethical approval number: NWU-00511-17-A9).

\section{Data analysis, results and interpretation}

The results of this study are provided for SA and Kenya.

\section{South African data}

Table 1 provides descriptive statistics, normality test, stationarity tests and auto-correlational tests for each of the three components of the EMP index for March 1999 to February 2017.

All three financial variables demonstrate non-normality but are stationary as demonstrated by Guru and Sarma (2013). They are skewed and show excess kurtosis (except interest rates). Significant Ljung-Box statistics for the series are shown for the rate of change exchange rate and rate of change interest rate. The series was modelled with ARMA modelling. Significant Ljung-Box statistics for the squared series are shown for the rate of change interest rate and rate of change reserves-to-M1. These will be dealt with appropriate $\mathrm{ARCH} /$ $\mathrm{GARCH}$ processes. The results for these are depicted in the next section. 


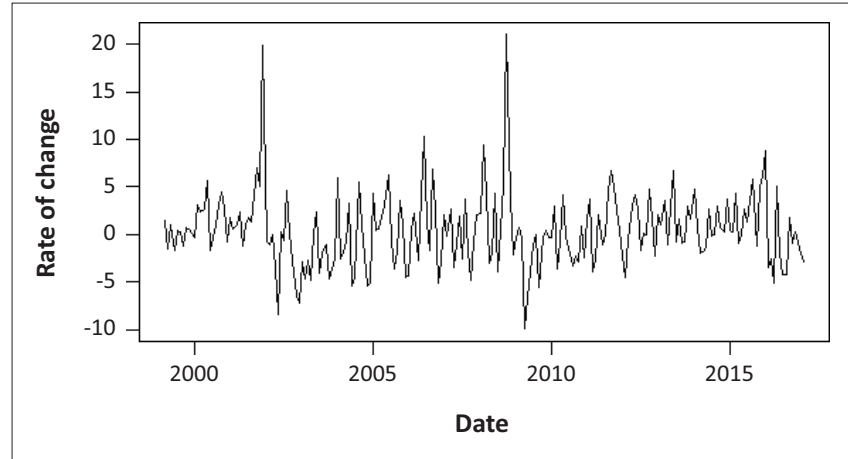

FIGURE 1: South Africa - Movement of the rate of change of monthly exchange rate.

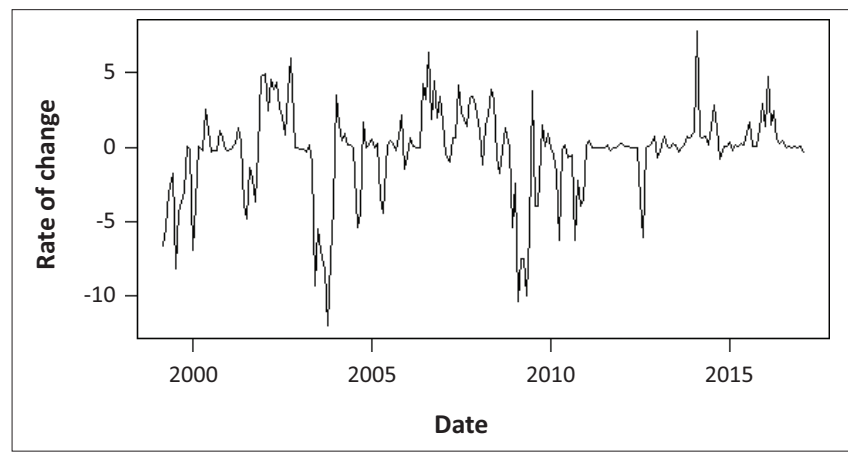

FIGURE 2: South Africa - Movement of the rate of change of monthly interest rates.

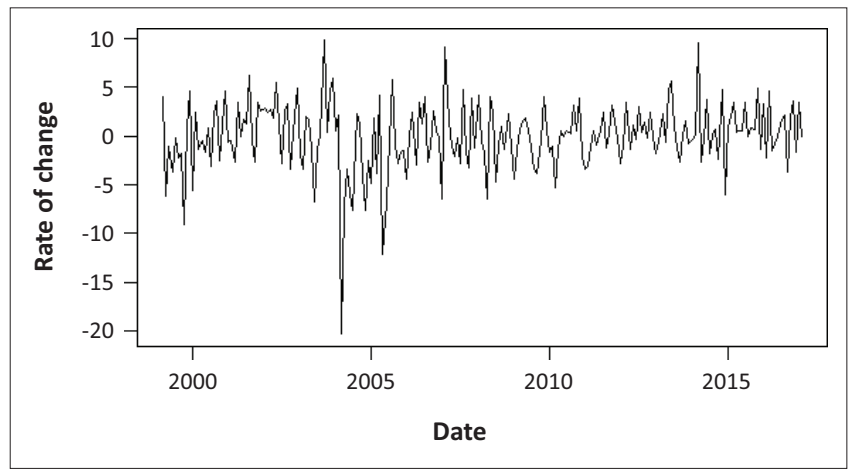

FIGURE 3: South Africa - Movement of the rate of change in reserves-to-M1 ratio.

Figures 1-3 provide the movements of monthly exchange rate, interest rates and reserves-to-M1 for the period 19992017. The exchange rate is compared to the US dollar. The exchange rates were stable over this period although increased volatility can be seen in 2002 and 2009. Regarding interest rates, the fluctuations are more volatile, especially in 2002-2003 and 2008. Similar results are depicted for the reserves-to-M1 ratio.

\section{Exchange market pressure index calculation}

Using the exchange rate, interest rate and reserves-to-M1 data from South Africa, the EMP index can be calculated.

However, before the respective standard deviations can be applied in the formula, we need to use the standardised standard deviations (for the variables in the EMP index that displayed conditional heteroscedasticity) to ensure that the assumption of iid holds. As such, the EMP index requires the standardisation of the time-varying volatilities. Consequently,
TABLE 2a: South Africa - Specification for the rate of change of exchange rate: A [MA(1)] model.

\begin{tabular}{lcc}
\hline Parameter & Estimate & Standard error \\
\hline $\mathrm{MA}(1)$ & & \\
Intercept & 0.282 & 0.1053 \\
$\mathrm{MA}(1)$ & 0.5008 & 0.0578 \\
\hline
\end{tabular}

Source: Guru, A. \& Sarma, M, 2013, Exchange market pressure in India, Discussion Papers in Economics 15, pp. 22-45

Note: $\mathrm{AIC}=4.0915 ; \mathrm{BIC}=4.1852$

$\mathrm{MA}$, moving average.

TABLE $2 \mathbf{b}$ : South Africa - Specification for the rate of change of exchange rate: A [MA(1)] model.

Weighted Ljung-Box test for residuals Weighted Ljung-Box test on squared residuals $\mathrm{Q}(1)=0.005(0.946) \quad \mathrm{Q}(10)=5.663(0.773)$

$Q(6)=3.820(0.701)$ $\mathrm{Q}(15)=6.999(0.935)$

$\mathrm{Q}(25)=20.523(0.719)$ $\mathrm{Q}(25)=9.411(0.997)$

Source: Guru, A. \& Sarma, M, 2013, Exchange market pressure in India, Discussion Papers in Economics 15, pp. 22-45

$\mathrm{MA}$, moving average.

TABLE 3a: South Africa - Specification for the rate of change of interest rate: A [AR(1)- GARCH(1,1)] model.

\begin{tabular}{lccc}
\hline Parameter & Estimate & Standard error & $p$ \\
\hline $\operatorname{AR}(1)$ - GARCH(1,1) & & & \\
$\mu$ & 0.1228 & 0.1053 & 0.2433 \\
AR(1) & 0.5008 & 0.0578 & 0.0000 \\
Omega & 0.1911 & 0.2095 & 0.3617 \\
Alpha 1 & 0.4216 & 0.1140 & 0.0002 \\
Beta 1 & 0.5774 & 0.0753 & 0.0000 \\
\hline
\end{tabular}

Source: Guru, A. \& Sarma, M, 2013, Exchange market pressure in India, Discussion Papers in Economics 15, pp. 22-45

Note: $\mathrm{AIC}=4.0915 ; \mathrm{BIC}=4.1852$

AIC, Akaike information criterion; ARCH, autoregressive conditional heteroscedasticity; BIC Bayesian information criterion; GARCH, generalised autoregressive conditional heteroskedasticity; LM, Lagrange Multiplier

TABLE 3b: South Africa - Specification for the rate of change of interest rate: A [AR(1)- GARCH(1,1)] model.

\begin{tabular}{lcc}
$\begin{array}{l}\text { Weighted Ljung-Box test } \\
\text { for residuals }\end{array}$ & $\begin{array}{c}\text { Weighted Ljung-Box test } \\
\text { on squared residuals }\end{array}$ & $\begin{array}{c}\text { Weighted ARCH } \\
\text { LM test }\end{array}$ \\
\hline$Q(1)=2.576(0.109)$ & $Q(1)=0.388(0.533)$ & $Q(3)=0.673(0.412)$ \\
$Q(6)=2.672(0.066)$ & $Q(15)=1.132(0.829)$ & $Q(5)=1.171(0.683)$ \\
$Q(25)=4.492(0.157)$ & $Q(25)=1.679(0.940)$ & $Q(7)=1.411(0.839)$ \\
\hline
\end{tabular}

Source: Guru, A. \& Sarma, M, 2013, Exchange market pressure in India, Discussion Papers in Economics 15, pp. 22-45

$\mathrm{ARCH}$, autoregressive conditional heteroscedasticity; $\mathrm{GARCH}$, generalised autoregressive conditional heteroskedasticity.

TABLE 4a: South Africa - Specification for the rate of change of forex reserves to M1 ratio: A GARCH[1,1] model.

\begin{tabular}{llcc}
\hline Parameter & Estimate & Standard error & $p$ \\
\hline GARCH(1,1) & & & \\
$\mu$ & 0.2068 & 0.2028 & 0.3079 \\
Omega & 0.3195 & 0.3004 & 0.2875 \\
Alpha 1 & 0.0466 & 0.0254 & 0.0667 \\
Beta 1 & 0.9219 & 0.0396 & 0.0000 \\
\hline
\end{tabular}

Source: Guru, A. \& Sarma, M, 2013, Exchange market pressure in India, Discussion Papers in Economics 15, pp. 22-45

Note: $\mathrm{AIC}=5.2325 ; \mathrm{BIC}=5.3107$

AIC, Akaike information criterion; BIC, Bayesian information criterion; GARCH, generalised autoregressive conditional heteroscedasticity.

the time series dynamics are displayed for each constituent of the series (Tables 2-4).

The $e_{t}$ series demonstrated autocorrelation with significant Ljung-Box statistics for the mean series, revealing a moving average (MA)[1] process (Table 1). 
TABLE 4b: South Africa - Specification for the rate of change of forex reserves to M1 ratio: A GARCH[1,1] model.

\begin{tabular}{lcc}
$\begin{array}{l}\text { Weighted Ljung-Box } \\
\text { test for residuals }\end{array}$ & $\begin{array}{c}\text { Weighted Ljung-Box test } \\
\text { on squared residuals }\end{array}$ & $\begin{array}{c}\text { Weighted ARCH } \\
\text { LM test }\end{array}$ \\
\hline$Q(1)=0.000(0.995)$ & $Q(1)=0.072(0.788)$ & $Q(3)=0.793(0.373)$ \\
$Q(2)=0.015(0.985)$ & $Q(5)=1.557(0.726)$ & $Q(5)=1.725(0.535)$ \\
$Q(5)=0.670(0.929)$ & $Q(9)=5.701(0.334)$ & $Q(7)=5.418(0.186)$ \\
\hline
\end{tabular}

Source: Guru, A. \& Sarma, M, 2013, Exchange market pressure in India, Discussion Papers in Economics 15, pp. 22-45

$\mathrm{ARCH}$, autoregressive conditional heteroscedasticity; GARCH, generalised autoregressive conditional heteroscedasticity; LM, Lagrange multiplier.

TABLE 5: South Africa - Descriptive and standard time series tests for exchange market pressure index: 1999-2017.

\begin{tabular}{lc}
\hline Variable & Results \\
\hline Mean & 0.3081 \\
Median & 0.4923 \\
Standard deviation & 8.2586 \\
Variance & 68.2044 \\
Minimum & -26.3520 \\
Maximum & 37.1180 \\
Skewness & 0.3167 \\
Kurtosis & 2.6897 \\
Normality & \\
Jarque-Bera & $71.363(0.00)$ \\
Stationarity & \\
ADF test statistic & $-5.2316(0.01)$ \\
PP test statistic & $-180.71(0.01)$ \\
ARCH LM test & \\
Lag 1 & $0.3960(0.529)$ \\
Autocorrelation test & \\
Ljung-Box Q statistic for series & \\
Q20 & $24.248(0.232)$ \\
Q30 & $43.481(0.053)$ \\
Heteroscedasticity test & \\
Ljung-Box statistic for squared series & \\
Q20 & $26.270(0.661)$ \\
Q30 & \\
\hline Source: Gur, A. \& Sarma $M, 2013$, Exchange market pressure & \\
\hline
\end{tabular}

Source: Guru, A. \& Sarma, M, 2013, Exchange market pressure in India, Discussion Papers in Economics 15, pp. 22-45

ADF, Augmented Dickey-Fuller test; PP, Phillips-Perron test; ARCH, autoregressive conditional heteroscedasticity; LM, Lagrange multiplier.

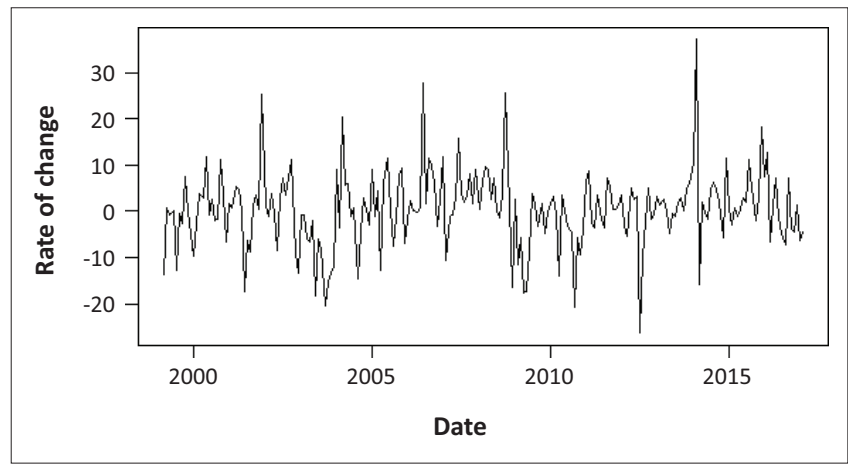

FIGURE 4: South Africa - Movement of the exchange market pressure index (1999-2017).

The $i_{t}$ series displayed autocorrelation with significant LjungBox statistics signifying an ARMA process. Moreover, the squared series also demonstrated serial correlation suggesting a GARCH effect (Table 1). The time series method of Box and Jenkins was applied and an appropriate model for the rate of changes in interest rate was found to be an AR(1)-GARCH(1,1) process. The information for this model and the diagnostic examination is presented in Table 3.

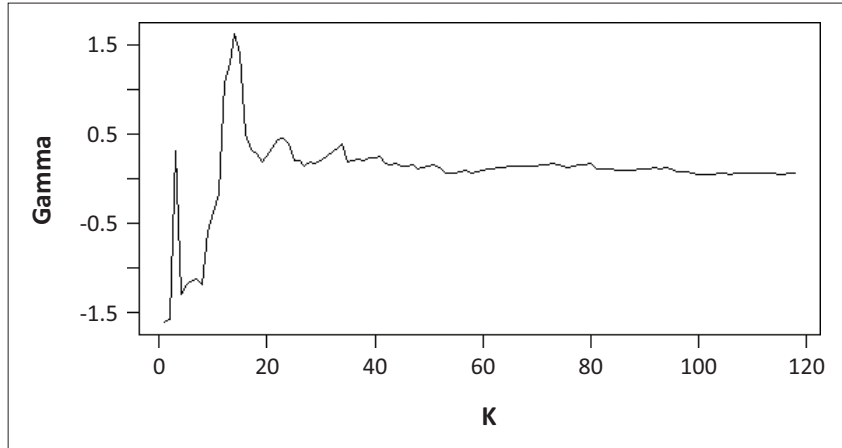

FIGURE 5: South Africa - Peak over threshold estimates to determine the threshold value.

Lastly, the $r_{t}$ series showed significant Ljung-Box statistics for the squared series (heteroscedasticity) demonstrating a GARCH [1,1] process. The process is depicted in Table 4.

The standardised standard deviations of the respective ARMA and/or GARCH processes for each factor of the EMP index are used for the calculation of the EMP index.

The calculation of the EMP index was performed in Microsoft Excel (2013) using the standardised standard deviations with no heteroscedasticity. Using these estimated volatilities and the EMP formula listed above, the EMP index series from 1999 to 2017 was calculated. The descriptive statistics for the series is depicted in Table 5 and the movement of the EMP index series is schematically demonstrated in Figure 4. The series is shown to be non-normally distributed with a positive skew. Other studies performed on the analysis of EMP similarly demonstrated non-Gaussian distributions (Guru \& Sarma 2013; Heinz \& Rusinova 2015; Pozo \& AmuedoDorantes 2003). The time series analysis reported in Table 4 demonstrates that the EMP series is stationary, with no autocorrelation for the series or squared series.

As demonstrated in Figure 4, the EMP index reveals more or less constant volatility during the entire period. Several spikes of depreciation (positive value of the EMP index) can be seen.

As we have studied the EMP index in South Africa from 1999 to 2017 , we now need to demonstrate the identification of a stress period. These are periods of extreme positive values in the EMP index. Periods of sustained stress over two or more periods are indicative of a currency crisis. The application of EVT will be used to demonstrate these periods of extreme pressure and/or currency crisis.

Extreme value theory: Peak over threshold analysis of the exchange market pressure index

The study by Guru and Sarma (2013) chose a threshold value of the largest $20 \%$. In our study, we decided to use a threshold value of $15 \%$ of the data to be extreme observations as our South African data set is less volatile than that presented by Guru and Sarma (2013). The tail threshold (largest 15\% of values) chosen is 7.00. This equates to the largest 35 values. From Figure 5, it is evident that the POT estimate levels off and becomes stable after 35 observations. 
TABLE 6: South Africa - Generalised Pareto distribution: Peak over threshold estimation results for the exchange market pressure series.

\begin{tabular}{lcccccc}
\hline $\begin{array}{l}\text { Percentage of observations } \\
\text { above the threshold (\%) }\end{array}$ & $\begin{array}{c}\text { Amount of observations } \\
\text { above the threshold }\end{array}$ & Threshold $(u)$ & $\begin{array}{c}\text { Shape } \\
\text { parameter }(\xi)\end{array}$ & $\begin{array}{c}\text { Scale } \\
\text { parameter }(\hat{\sigma})\end{array}$ & $\begin{array}{c}\boldsymbol{P}=0.0595 \text { th } \\
\text { percentile }\end{array}$ & $\begin{array}{c}\boldsymbol{P}=\mathbf{0 . 0 1} \text { 99th } \\
\text { percentile }\end{array}$ \\
\hline 15 & 35 & 7.00 & 0.400 & 3.415 & 12.13 \\
\hline
\end{tabular}

Source: Guru, A. \& Sarma, M, 2013, Exchange market pressure in India, Discussion Papers in Economics 15, pp. 22-45

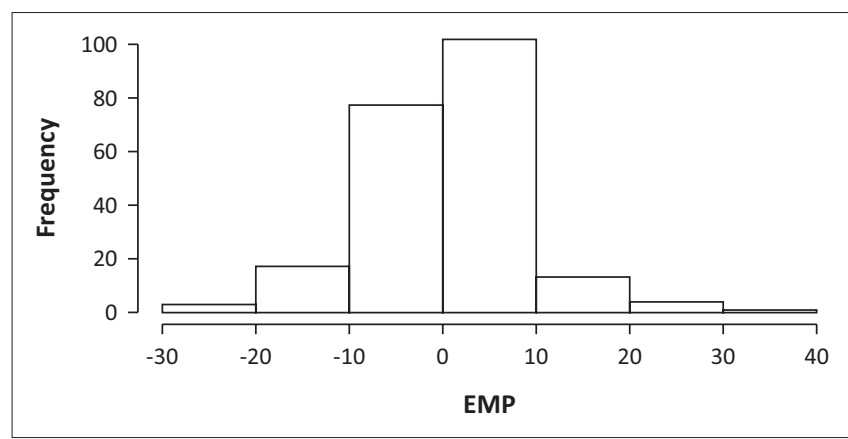

EMP, exchange market pressure.

FIGURE 6: South Africa - Histogram of the exchange market pressure index for 1999-2017.

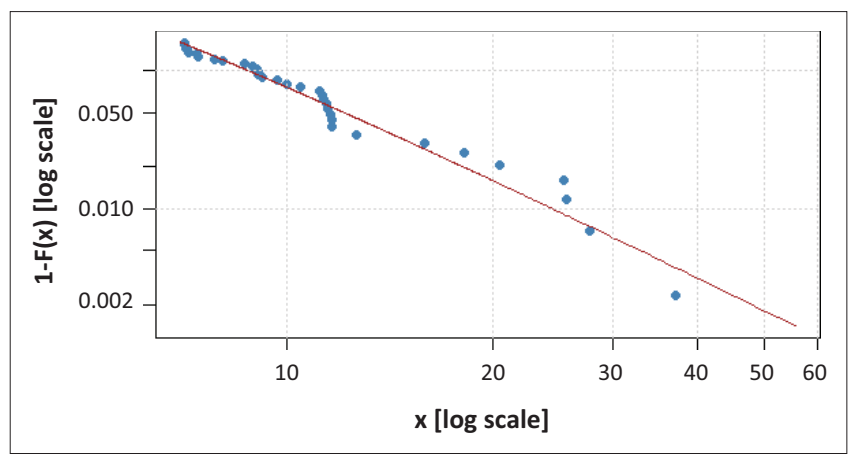

FIGURE 7: South Africa - Diagnostic plot for peak over threshold analysis: Tail of the underlying distribution.

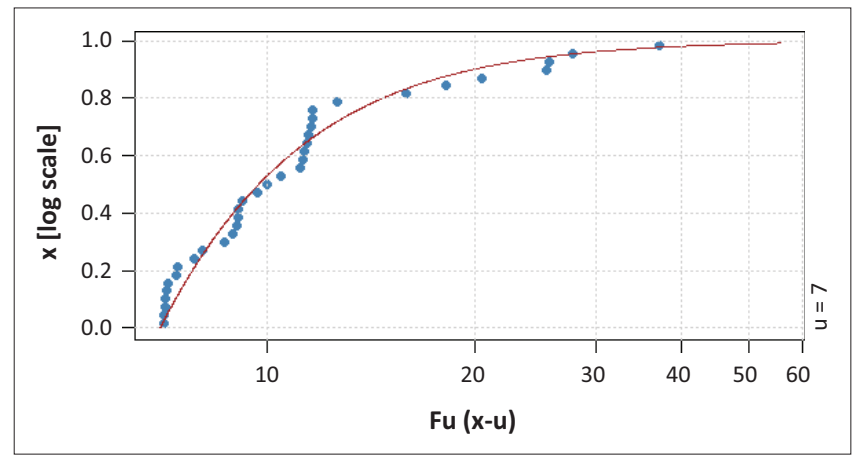

FIGURE 8: South Africa - Diagnostic plot for peak over threshold analysis: Excess distribution.

Using this threshold value, we proceeded to fit a GPD to the values exceeding 7.00. The maximum likelihood estimation method was utilised. The package fExtremes (Wuertz 2013) was used for the analysis. Consequently, the estimated parameters were used to calculate crisis thresholds at the 95th and 99th percentiles. The formula used for the POT method is as follows:

$X_{p}=\mu+\sigma / \xi\left[(n p / k)^{-\xi}-1\right]$

where $n=216$

$k=35$ (number of observations above the threshold $\mu$ )

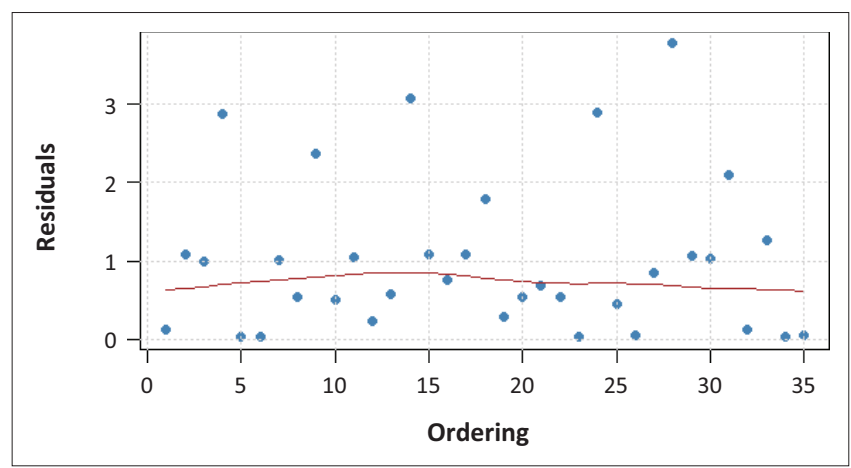

FIGURE 9: South Africa - Diagnostic plot for peak over threshold analysis: Scatterplot of the residuals.

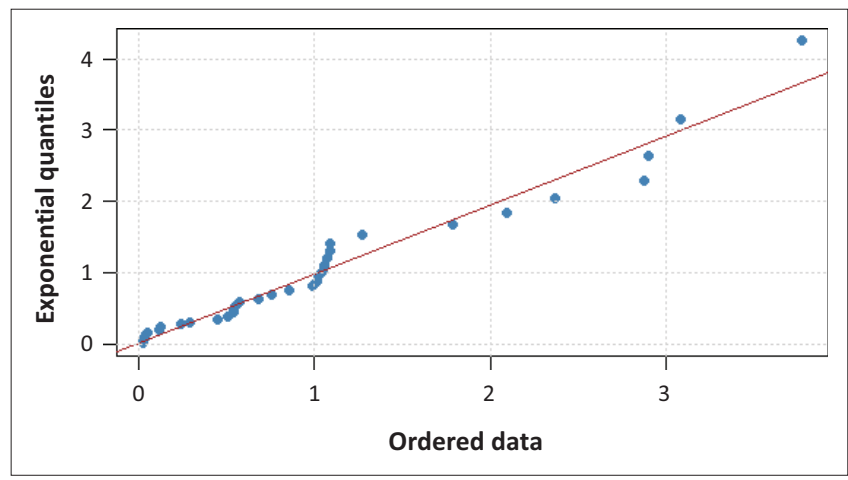

FIGURE 10: South Africa - Diagnostic plot for peak over threshold analysis: QQplot of the residuals.

$\hat{\sigma}, \hat{\xi}$ : maximum likelihood estimates of the GPD parameters (see Table 6).

Usually, when using the POT approach, one would implement the probability stress threshold fixed at 0.05 (95th percentile) or at 0.01 (99th percentile). Using the Equation 6, the entire tail region can be calculated using different $p$-quantiles. Table 6 depicts the parameters estimated by the GPD.

The shape parameter was shown to be 0.400 , which is a positive number and indicative of the heavy-tailed and Frechet distribution. The results in Table 5 also revealed nonnormality (Jarque-Bera statistic) and excess kurtosis. The histogram of the EMP index confirms the positive skew and kurtosis (Figure 6).

The following four figures demonstrate the diagnostic plots for the fitted distribution (Figures 7-10). The observations are fitted well for the tail and excess of the underlying distribution (Figures 7 and 8). The figures demonstrate a good fit with the POT method (using maximum likelihood estimation), with the use of the top 15\% values. In Figure 9, the scatterplot of the residuals is random and spread, with the red line nearly parallel to the $\mathrm{X}$-axis indicating a good fit. The residuals in 
TABLE 7: South Africa - Estimated tail quantiles of the exchange market pressure index: 1999-2017.

\begin{tabular}{|c|c|c|c|c|}
\hline $\begin{array}{l}\text { Probability } \\
\text { level }\end{array}$ & $\begin{array}{c}\text { Estimated } \\
\text { quantiles (EVT) }\end{array}$ & $\begin{array}{l}\text { Empirical } \\
\text { quantiles }\end{array}$ & $\begin{array}{c}\text { Normal distribution } \\
\text { quantiles }\end{array}$ & $\begin{array}{c}\text { Estimated } \\
\text { quantile (Hill) }\end{array}$ \\
\hline 0.80 & 6.31 & 5.45 & 0.842 & 5.83 \\
\hline 0.81 & 6.47 & 5.98 & 0.878 & 5.99 \\
\hline 0.82 & 6.65 & 6.12 & 0.915 & 6.17 \\
\hline 0.83 & 6.84 & 6.30 & 0.954 & 6.37 \\
\hline 0.84 & 7.04 & 6.45 & 0.995 & 6.58 \\
\hline 0.85 & 7.27 & 7.12 & 1.036 & 6.81 \\
\hline 0.86 & 7.51 & 7.15 & 1.080 & 7.07 \\
\hline 0.87 & 7.79 & 7.41 & 1.126 & 7.36 \\
\hline 0.88 & 8.09 & 7.86 & 1.175 & 7.69 \\
\hline 0.89 & 8.43 & 8.68 & 1.227 & 8.06 \\
\hline 0.90 & 8.82 & 9.05 & 1.282 & 8.49 \\
\hline 0.91 & 9.26 & 9.19 & 1.341 & 8.98 \\
\hline 0.92 & 9.78 & 10.03 & 1.405 & 9.58 \\
\hline 0.93 & 10.41 & 11.17 & 1.476 & 10.29 \\
\hline 0.94 & 11.17 & 11.32 & 1.555 & 11.19 \\
\hline 0.95 & 12.13 & 11.50 & 1.645 & 12.35 \\
\hline 0.96 & 13.40 & 11.65 & 1.751 & 13.94 \\
\hline 0.97 & 15.23 & 15.89 & 1.881 & 16.29 \\
\hline 0.98 & 18.18 & 20.50 & 2.054 & 20.29 \\
\hline 0.99 & 24.48 & 25.73 & 2.326 & 29.54 \\
\hline 0.9950 & 32.80 & 27.80 & 2.576 & 43.00 \\
\hline 0.9990 & 63.84 & 37.12 & 3.090 & 102.83 \\
\hline
\end{tabular}

Source: Guru, A. \& Sarma, M, 2013, Exchange market pressure in India, Discussion Papers in Economics 15, pp. 22-45

Note: Bold values signify the 95 th and 99 th percentile. Hill estimate is discussed in the next section.

EVT, extreme value theory.

TABLE 8: South Africa - Extreme pressure or crisis of the exchange market pressure index with individual components for each month.

\begin{tabular}{lcccc}
\hline $\begin{array}{l}\text { Month of extreme } \\
\text { EMP }\end{array}$ & EMP & \multicolumn{3}{c}{ Component of the EMP index } \\
\cline { 3 - 5 } & & $\begin{array}{c}\text { Rate-of-change } \\
\text { exchange rate }\end{array}$ & $\begin{array}{c}\text { Rate-of-change } \\
\text { interest rate }\end{array}$ & $\begin{array}{c}\text { Rate-of-change } \\
\text {-reserves-to-M1 }\end{array}$ \\
\hline December 2001 & 25.43 & $\mathbf{1 9 . 8 6}$ & 4.73 & 2.53 \\
\hline March 2004 & 20.50 & -2.02 & 0.43 & -20.37 \\
June 2006 & 27.80 & 10.32 & 4.29 & 1.22 \\
\hline June 2007 & 15.89 & 1.97 & 4.18 & -0.23 \\
October 2008 & 25.73 & $\mathbf{2 1 . 0 1}$ & 1.29 & -1.41 \\
\hline February 2014 & 37.12 & 0.69 & $\mathbf{7 . 7 7}$ & 0.03 \\
\hline December 2015 & 18.21 & $\mathbf{6 . 0 8}$ & 2.98 & -1.36 \\
February 2016 & 12.66 & -3.41 & 4.78 & -2.30 \\
\hline
\end{tabular}

Source: Guru, A. \& Sarma, M, 2013, Exchange market pressure in India, Discussion Papers in Economics 15, pp. 22-45

Note: The bold cells show the individual components mostly responsible for the high EMP values during the respective periods.

EMP, exchange market pressure.

the Quantile-Quantile (QQ)-plot are also fitted close to the $45^{\circ}$ line in the next figure (Figure 10).

The estimated 95th percentile and 99th percentile for the EMP index are 12.13 and 24.48, respectively. These are indicative of the crisis threshold or stress periods at 0.05 and 0.01 probabilities, respectively. Exchange market pressure values greater than these thresholds would indicate a period of stress or crisis at the corresponding probability levels. Table 7 demonstrates that the EVT quantiles fit the empirical quantiles better than the normal distribution quantiles as reported by Guru and Sarma (2013). The normal distribution crisis-based thresholds are very low and, therefore, many false alarms would be raised. From Table 7, it is clear that the model is accurate for values up to the 95th percentile, and that the accuracy of the estimated quantiles for the 96th to 99th percentile decreases. However, the model still provides a better fit when compared to the normal distribution.

In the current study, an EMP index greater than 12.13 would be indicative of currency stress at $p=0.05$ (GPD POT). As such, eight periods of stress are highlighted. At $p=0.01$ (values greater than 24.48), four periods of extreme stress or crisis are highlighted between 1999 and 2017 (GPD POT). The months affected are December 2001, March 2004, June 2006, June 2007, October 2008, February 2014, December 2015 and February 2016. If currency crisis is defined as periods of two consecutive months of stress, no such periods are found. The four periods of extreme pressure with $p=0.01$ are December 2001, June 2006, October 2008 and February 2014. If the current study had used normally distributed thresholds at $p=0.05,92$ exceedances would have been raised, causing many false positive warnings. If the Hill estimate was used (right hand column), the same periods of time would have been selected at $p=0.05$, but at $p=0.01$ only one period of extreme pressure is flagged.

In the next section, the stress period $(p=0.05)$ is reflected in Table 8 with the individual factors of the EMP index. The bold cells show the individual components mostly responsible for the high EMP values during the respective periods. In December 2001, June 2006, October 2008 and December 2015, the rates of change in exchange rates were the most influential values on the EMP index. In June 2007, February 2014 and February 2016, the rates of change in interest rates were the most powerful values for driving the EMP index into an extreme positive index. Lastly, in March 2004, the rate-of-change in reserves-to-M1 was the most prominent component to influence the EMP index. Although a near currency crisis was elicited in January and February 2014, values of the EMP index returned to normal in March 2014. Also, fortunately the value for the EMP index for January 2014 was not indicative of severe currency pressure $(p=0.01)$.

Similar studies showing the results for periods of stress or crisis are also reported in Asian studies (Guru \& Sarma 2013; Pozo \& Amuedo-Dorantes 2003). The study by Guru and Sarma (2013) also reported the influence of the individual components in periods of extreme pressure.

\section{Extreme value theory: Hill estimate}

Quantiles calculated according to the Hill estimate are also provided in Table 7. Figure 11 concurs with the earlier decision to use a threshold value of 7.00 (i.e. $K=35$ ). A parallel line to the $\mathrm{X}$-axis can be drawn up to $k=35$. The largest 35 values were sorted from the largest to the smallest (rank ordered), and Equation 4 (Hill 1975; Kang \& Song 2017) was applied to determine the Hill estimate (Xi [Hill]). 
The Hill estimate calculated is 0.54172 .

The 100pth quantile using the Hill estimator was also computed according to Equation 5 (Kang \& Song 2017). The analysis was also run in $\mathrm{R}$ (package ReIns).

From Table 7, it is clear that the GPD POT method outperforms the Hill estimate (compared to the empirical quantiles) at higher quantiles $(p=0.001$ to $p=0.10$ ) where the risk of extreme crises becomes more formidable. However, there are instances where the Hill estimate provides a better index compared to the GPD POT method and especially so at percentiles of $0.80-0.89$.

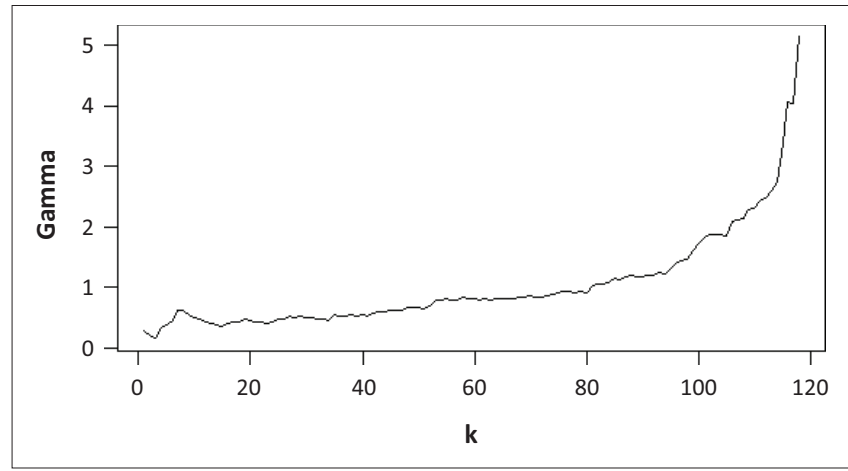

FIGURE 11: South Africa - Hill estimate to obtain cut-off between tail and central observations.

TABLE 9: Kenya - Descriptive statistics and time series tests of components of exchange market pressure.

\begin{tabular}{|c|c|c|c|}
\hline Variable & $\begin{array}{l}\text { Rate of change of } \\
\text { exchange rate }\end{array}$ & $\begin{array}{l}\text { Rate of change of } \\
\text { interest rate }\end{array}$ & $\begin{array}{c}\text { Rate of change in } \\
\text { reserves-to-M1 }\end{array}$ \\
\hline \multicolumn{4}{|l|}{ Descriptive statistics } \\
\hline Mean & 1.2113 & 1.7749 & 0.1961 \\
\hline Median & 0.3675 & 0.0000 & 0.2454 \\
\hline Standard deviation & 4.1471 & 22.7226 & 4.7410 \\
\hline Minimum & -7.9584 & -54.9211 & -22.9134 \\
\hline Maximum & 31.4292 & 230.0882 & 14.4729 \\
\hline Skewness & 2.5134 & 5.2549 & -0.6876 \\
\hline Excess kurtosis & 14.1578 & 50.1740 & 2.5784 \\
\hline Jarque-Bera & $1915.7(0.00)^{*}$ & $22254(0.00)^{*}$ & $73.487(0.00)^{*}$ \\
\hline \multicolumn{4}{|l|}{ Stationarity test } \\
\hline ADF test statistic & $-5.2867(0.01)^{*}$ & $-4.8719(0.01)^{*}$ & $-5.8741(0.01)^{*}$ \\
\hline PP test statistic & $-229.2(0.01) *$ & $-167.92(0.01)^{*}$ & $-167.92(0.01)^{*}$ \\
\hline \multicolumn{4}{|l|}{ ARCH LM test } \\
\hline Lag 1 & $0.0147(0.904)$ & $0.0008(0.977)$ & $1.1990(0.2735)$ \\
\hline Lag 5 & $0.3515(0.997)$ & 0.1289 (0.999) & $1.7745(0.879)$ \\
\hline Lag 10 & 1.3861 (0.999) & $0.2248(1.000)$ & $3.9088(0.9514)$ \\
\hline \multicolumn{4}{|l|}{ Autocorrelation test } \\
\hline \multicolumn{4}{|c|}{ Ljung-Box Q statistic for series } \\
\hline$Q(20)$ & $18.143(0.578)$ & $21.077(0.393)$ & $24.972(0.203)$ \\
\hline$Q(30)$ & $31.899(0.372)$ & $31.745(0.380)$ & $30.295(0.451)$ \\
\hline$Q(40)$ & $50.044(0.133)$ & $35.020(0.694)$ & $42.084(0.381)$ \\
\hline \multicolumn{4}{|c|}{ Heteroscedasticity test } \\
\hline \multicolumn{4}{|c|}{ Ljung-Box $Q$ statistics for squared series } \\
\hline$Q(20)$ & $2.045(0.999)$ & $0.593(1.000)$ & $7.707(0.994)$ \\
\hline $\mathrm{Q}(30)$ & $17.158(0.971)$ & $1.286(1.000)$ & $26.071(0.672)$ \\
\hline$Q(40)$ & $18.018(0.999)$ & $1.878(1.000)$ & $31.009(0.845)$ \\
\hline
\end{tabular}

Source: Guru, A. \& Sarma, M, 2013, Exchange market pressure in India, Discussion Papers in Economics 15, pp. 22-45

ADF, Augmented Dickey-Fuller test; PP, Phillips-Perron test; ARCH, autoregressive conditional heteroscedasticity; LM, Lagrange multiplier.

$*$, values significantly less than 0.05 .

\section{Kenyan data}

Table 9 provides information about descriptive statistics, normality, stationarity and serial correlation for the three components of the EMP index for August 2008 to February 2017. All three financial variables demonstrate non-normality but are stationary. They are skewed and show excess kurtosis (except rate of change in reserves-to-M1). No significant Ljung-Box statistics for the series or squared series for any lags are shown for any of the three components of the EMP index. As a result, all variables demonstrate no time-varying volatilities and do not need to be modelled with ARMA and/ or ARCH/GARCH processes.

Figures 12-14 provide the movements of monthly exchange rate, interest rates and reserves-to-M1 for 2000-2017. The exchange rate is compared to the US dollar. The exchange rates were stable over this period although increased volatility can be seen in the middle of 2014. For the second component, namely interest rates, the fluctuations are less

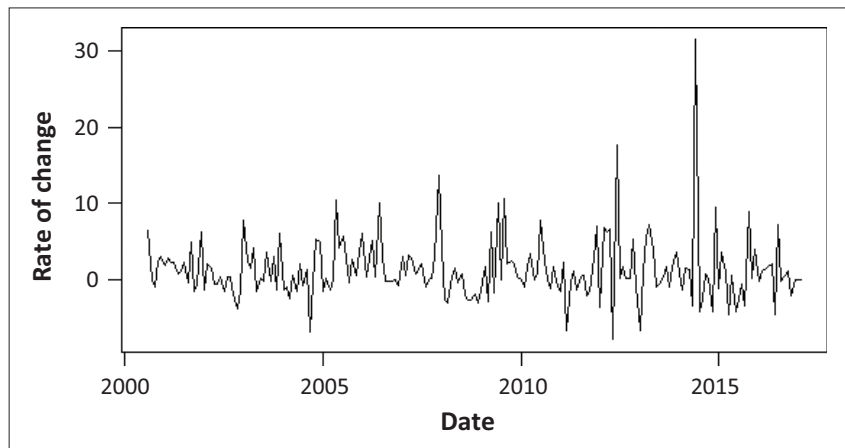

FIGURE 12: Kenya - Movement of the rate of change of monthly exchange rate.

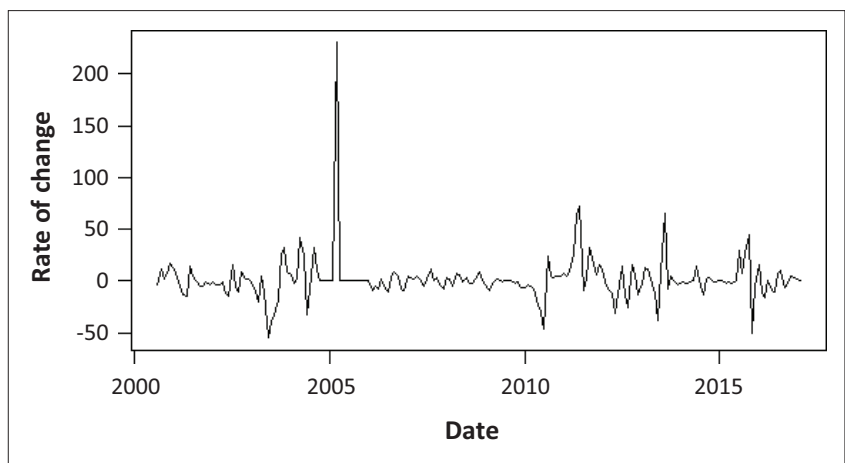

FIGURE 13: Kenya - Movement of the rate of change of monthly interest rates.

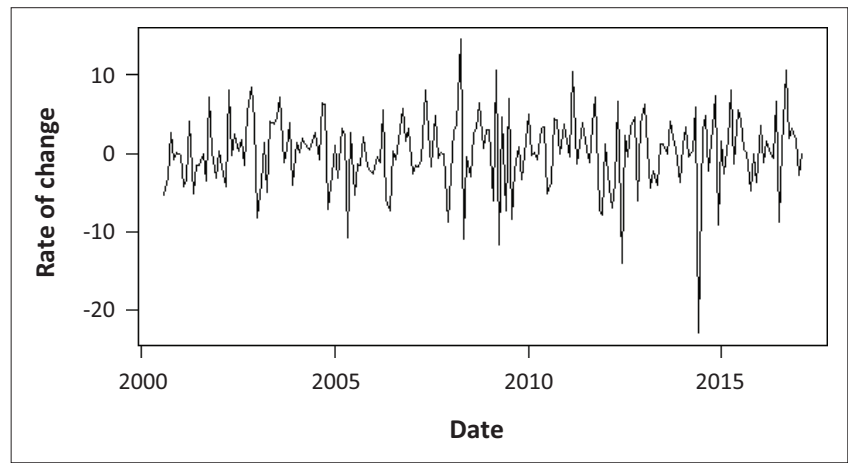

FIGURE 14: Kenya - Movement of the rate of change in reserves-to-M1 ratio. 
volatile, but large increases are observed throughout 2005. Although Figure 14 demonstrates the most volatility for reserves-to-M1 ratio, the fluctuations are relatively stable over time, with only one large negative spike in mid-2014.

\section{Calculation of the exchange market pressure index}

Using the three components of the EMP index for Kenya, the exchange market pressure for monthly data can be calculated (Equation 1).

As stated earlier, the respective standard deviations can only be applied when each variable is independent and identically distributed. Consequently, EMP index requires the

TABLE 10: Kenya - Descriptive and standard time series tests for exchange market pressure index: August 2000 to February 2017.

\begin{tabular}{lc}
\hline Variable & Result \\
\hline Mean & 1.3637 \\
Median & 0.6002 \\
Standard deviation & 8.7584 \\
Variance & 76.7098 \\
Minimum & -19.4800 \\
Maximum & 54.0353 \\
Skewness & 1.6646 \\
Kurtosis & 7.0402 \\
Normality & \\
Jarque-Bera & $516.23(0.00)^{*}$ \\
Stationarity & \\
ADF test statistic & $-5.66(0.01)^{*}$ \\
PP test statistic & $-224.56(0.01)^{*}$ \\
ARCH LM test & \\
Lag 1 & $0.004(0.95)$
\end{tabular}

Autocorrelation test

Ljung-Box Q statistic for series

Q20

$18.281(0.569)$

Q30

$27.066(0.620)$

Heteroscedasticity test

Ljung-Box statistic for squared series

Q20

4.850 (0.999)

Q30

$17.153(0.971)$

Source: Guru, A. \& Sarma, M, 2013, Exchange market pressure in India, Discussion Papers in Economics 15, pp. 22-45

ADF, Augmented Dickey-Fuller test; PP, Phillips-Perron test; ARCH, autoregressive conditional heteroscedasticity; LM, Lagrange multiplier.

$*$, values significantly less than 0.05

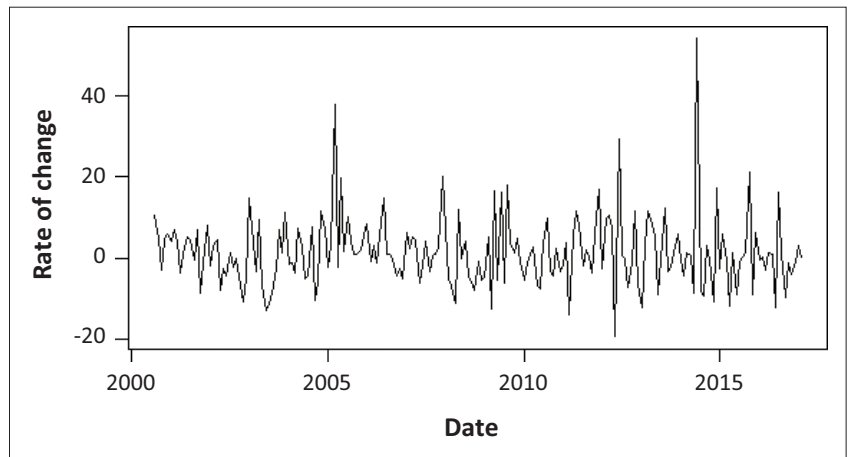

FIGURE 15: Kenya - Movement of the exchange market pressure index (August 2000-February 2017). standardisation of the time-varying volatilities (Guru \& Sarma 2013). None of the three variables for the Kenyan data displayed time-varying volatility for the mean and series (no heteroscedasticity).

The EMP index series was calculated from August 2000 to February 2017. The descriptive statistics for the series (Table 10) and a schematic presentation of the EMP index (Figure 15) are provided. The results of the series show that it is not normally distributed with a positive skew. A large value for kurtosis is reported. The time series analysis depicted in Table 10 reveals that the series is stationary with no serial correlation for the mean or squared series.

The figure of the EMP index illustrates relatively constant volatility during the studied period. Several spikes of depreciation (positive value of the EMP index) are shown in early 2003 and mid-2014. These are discussed in greater detail in the next section. Extreme value theory was applied to demonstrate possible periods of extreme pressure and/or currency crisis.

\section{Extreme value theory: Peak over threshold analysis of the exchange market pressure index}

For the Kenyan data, the researcher used a threshold value of $20 \%$ similar to the study by Guru and Sarma (2013). The data set contains 199 observations. Twenty per cent of 199 equates to 40 values. Consequently, the threshold value for the Kenyan data set is 6.50. From Figure 16, it is clear that the POT estimate levels off and becomes stable after 40 observations. Subsequently, a GPD to the values exceeding 6.50 can be fitted (Equation 6). The maximum likelihood estimation method is utilised.

Table 11 depicts the parameters estimated by the GPD.

The shape parameter is 0.166 , which is a positive number and indicative of a Frechet (heavy-tailed distribution). The results in Table 10 also reveal non-normality and excess kurtosis. The histogram reiterates a positive skew and is leptokurtic (Figure 17).

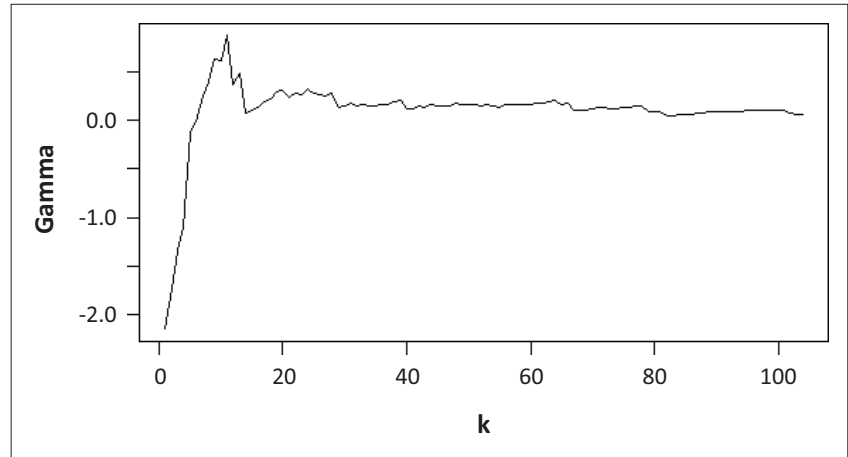

FIGURE 16: Kenya - Peak over threshold estimates to determine the threshold value.

TABLE 11: Kenya - Generalised Pareto distribution: Peak over threshold estimation results for the exchange market pressure series of the Kenyan data.

\begin{tabular}{lccccc}
\hline $\begin{array}{l}\text { Percentage of observations } \\
\text { above the threshold }(\%)\end{array}$ & $\begin{array}{c}\text { Number of observations } \\
\text { above the threshold }\end{array}$ & Threshold $(u)$ & $\begin{array}{c}\text { Shape }(\hat{\xi}) \\
\text { parameter }(\hat{\xi})\end{array}$ & $\begin{array}{c}\text { Scale } \\
\text { parameter }(\hat{\sigma})\end{array}$ & $\begin{array}{c}\boldsymbol{P}=0.05 \text { 95th } \\
\text { percentile }\end{array}$ \\
\hline 20 & 40 & 6.50 & 0.1662 & $\begin{array}{c}\boldsymbol{P}=\mathbf{0 . 0 1} \text { 99th } \\
\text { percentile }\end{array}$ \\
\hline
\end{tabular}

Source: Guru, A. \& Sarma, M, 2013, Exchange market pressure in India, Discussion Papers in Economics 15, pp. 22-45 


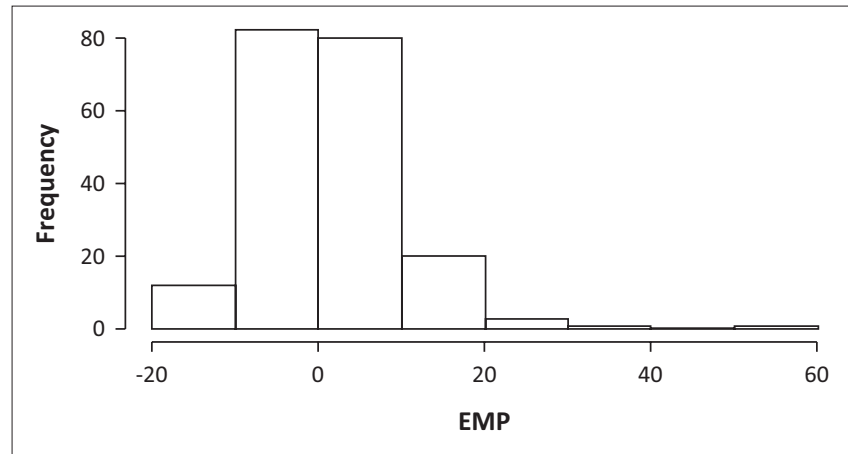

EMP, exchange market pressure.

FIGURE 17: Kenya - Histogram of the Kenyan exchange market pressure index for 2000-2017.

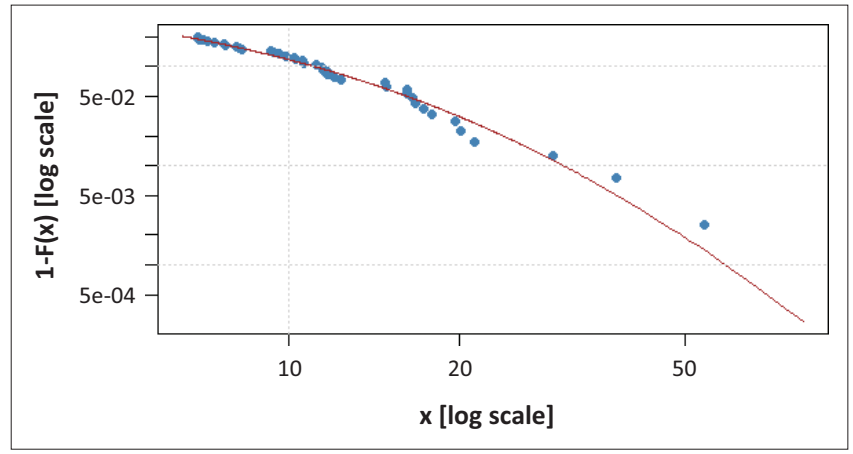

FIGURE 18: Diagnostic plot for peak over threshold analysis: Tail of the underlying distribution

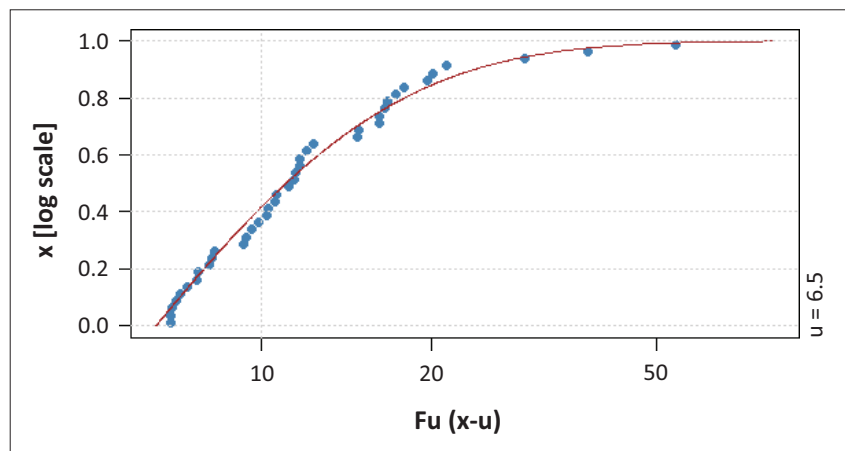

FIGURE 19: Kenya - Diagnostic plot for peak over threshold analysis: Excess distribution.

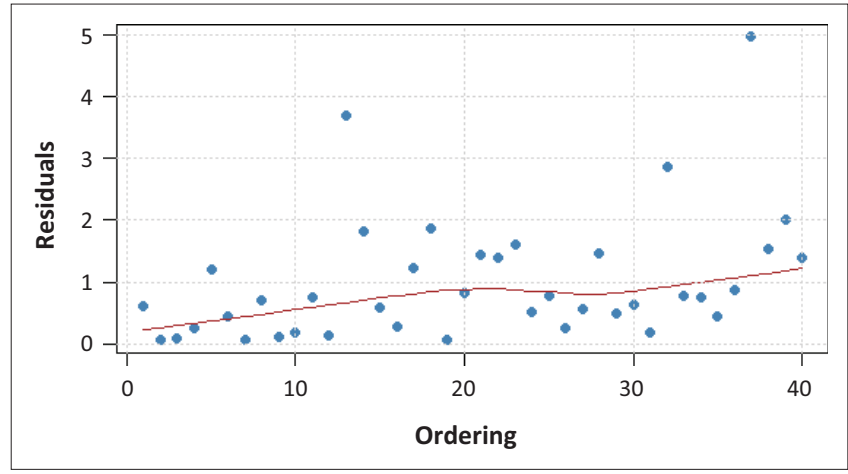

FIGURE 20: Kenya - Diagnostic plot for peak over threshold analysis: Scatterplot of the residuals.

Figures 18-21 demonstrate the diagnostic plots for the GPD (POT) fitted distribution for Kenya. The observations exceeding the threshold value of 6.50 are fitted well for the

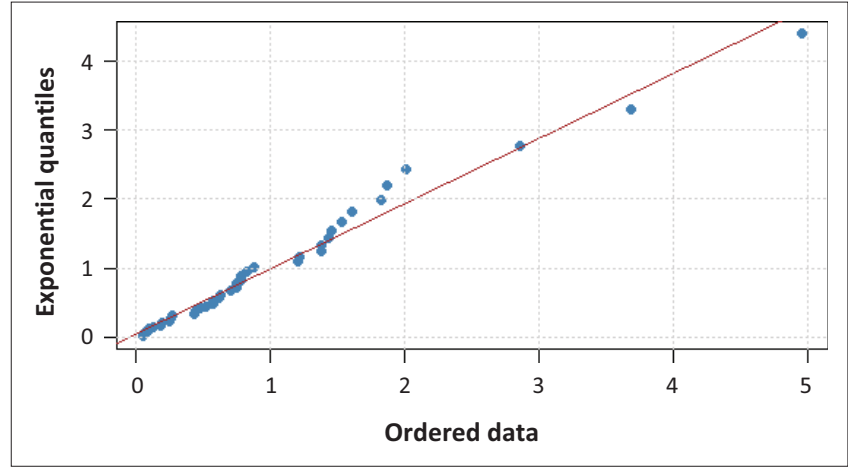

FIGURE 21: Kenya - Diagnostic plot for peak over threshold analysis: QQ-plot of the residuals.

TABLE 12: Kenya - Estimated tail quantiles of the exchange market pressure index.

\begin{tabular}{|c|c|c|c|c|}
\hline $\begin{array}{l}\text { Probability } \\
\text { level }\end{array}$ & $\begin{array}{c}\text { Estimated } \\
\text { quantiles (EVT) }\end{array}$ & $\begin{array}{l}\text { Empirical } \\
\text { quantiles }\end{array}$ & $\begin{array}{l}\text { Normal distribution } \\
\text { quantiles }\end{array}$ & $\begin{array}{c}\text { Estimated } \\
\text { quantile (Hill) }\end{array}$ \\
\hline 0.80 & 6.53 & 6.18 & 0.842 & 6.28 \\
\hline 0.81 & 6.85 & 6.91 & 0.878 & 6.51 \\
\hline 0.82 & 7.12 & 7.08 & 0.915 & 6.75 \\
\hline 0.83 & 7.55 & 7.36 & 0.954 & 7.02 \\
\hline 0.84 & 7.94 & 7.73 & 0.995 & 7.31 \\
\hline 0.85 & 8.35 & 8.16 & 1.036 & 7.64 \\
\hline 0.86 & 8.80 & 9.31 & 1.080 & 8.01 \\
\hline 0.87 & 9.29 & 9.62 & 1.126 & 8.42 \\
\hline 0.88 & 9.83 & 10.23 & 1.175 & 8.90 \\
\hline 0.89 & 10.42 & 10.55 & 1.227 & 9.44 \\
\hline 0.90 & 11.07 & 11.18 & 1.282 & 10.07 \\
\hline 0.91 & 11.81 & 11.46 & 1.341 & 10.82 \\
\hline 0.92 & 12.65 & 11.70 & 1.405 & 11.72 \\
\hline 0.93 & 13.62 & 12.37 & 1.476 & 12.83 \\
\hline 0.94 & 14.77 & 14.85 & 1.555 & 14.25 \\
\hline 0.95 & 16.17 & 16.13 & 1.645 & 16.14 \\
\hline 0.96 & 17.94 & 16.71 & 1.751 & 18.78 \\
\hline 0.97 & 20.32 & 17.92 & 1.881 & 22.84 \\
\hline 0.98 & 23.87 & 20.06 & 2.054 & 30.09 \\
\hline 0.99 & 30.53 & 29.17 & 2.326 & 48.21 \\
\hline 0.9950 & 37.99 & 37.88 & 2.576 & 77.25 \\
\hline 0.9990 & 59.05 & 54.04 & 3.090 & 230.85 \\
\hline
\end{tabular}

Source: Guru, A. \& Sarma, M, 2013, Exchange market pressure in India, Discussion Papers in Economics 15, pp. 22-45

EVT, extreme value theory.

tail and excess of the underlying distribution (Figures 18 and 19). The scatterplot of the residuals (Figure 20) is random and spread, with the red line nearly parallel to the $\mathrm{X}$-axis indicating a good fit. The residuals in the QQ-plot are also fitted close to the $45^{\circ}$ line in Figure 21 .

The estimated 95th percentile and 99th percentile for the EMP index are 16.17 and 30.53. Exchange market pressure values greater than these percentile-based thresholds would indicate a period of stress or crisis at the corresponding probability levels. Table 12 demonstrates that the EVT quantiles fit the empirical quantiles better than the normal distribution quantiles. The 95th and 9th percentile values are provided in bold in Table 12. The Hill estimated quantiles are discussed in the next section.

In this study, an EMP index greater than 16.17 would be indicative of currency stress at $p=0.05$ (GPD POT). As such, 
TABLE 13: Kenya - Extreme pressure or crisis of the exchange market pressure (EMP) index with individual components for each month.

\begin{tabular}{lcccc}
\hline $\begin{array}{l}\text { Month of } \\
\text { extreme EMP }\end{array}$ & EMP & \multicolumn{3}{c}{ Component of the EMP index } \\
\cline { 3 - 5 } & & $\begin{array}{c}\text { Rate-of-change } \\
\text { exchange rate }\end{array}$ & $\begin{array}{c}\text { Rate-of-change } \\
\text { interest rate }\end{array}$ & $\begin{array}{c}\text { Rate-of-change } \\
\text { Reserves-to-M1 }\end{array}$ \\
\hline March 2005 & 25.43 & -1.41 & $\mathbf{1 5 . 2 6}$ & 3.09 \\
May 2005 & 19.68 & $\mathbf{1 0 . 3 0}$ & 0 & -10.73 \\
\hline December 2007 & 20.06 & $\mathbf{1 3 . 6 0}$ & -6.99 & -8.84 \\
April 2009 & 16.57 & 6.21 & 0.55 & -11.73 \\
August 2009 & 17.92 & $\mathbf{1 0 . 6 4}$ & 0 & -8.32 \\
November 2011 & 10.23 & 2.86 & $\mathbf{6 . 6 3}$ & -7.05 \\
June 2012 & 29.17 & $\mathbf{1 7 . 6 1}$ & -3.33 & -13.91 \\
June 2014 & 20.50 & $\mathbf{3 1 . 4 3}$ & $\mathbf{1 4 . 0 4}$ & -22.91 \\
December 2014 & 17.28 & $\mathbf{9 . 5 0}$ & -0.83 & -9.07 \\
October 2015 & 21.23 & $\mathbf{8 . 7 9}$ & $\mathbf{1 5 . 1 9}$ & -4.79 \\
\hline
\end{tabular}

Source: Guru, A. \& Sarma, M, 2013, Exchange market pressure in India, Discussion Papers in Economics 15, pp. 22-45

10 periods of stress are identified. At $p=0.01$ (values greater than 30.53), two periods of extreme stress are identified between 2000 and 2017 (GPD POT). The months affected are March and May 2005, December 2007, April 2009, August 2009, November 2011, June 2012, June and December 2014 and October 2015. No period of currency crisis was defined, which is periods of two consecutive months of stress. The two periods of extreme pressure $(p=0.01)$ are March 2005 and June 2014. If the current study had employed normally distributed thresholds $(p=0.05), 82$ exceedances would have been raised, causing many unnecessarily flagged periods. The same periods are flagged when the Hill estimate is used for the 95th percentile. However, at the 99th percentile, no time periods demonstrate pressure situations from 2000 to 2017.

Because the EMP index and extreme periods of stress have been identified, it is possible to explore in more detail what economic activities transpired at this time. Table 13 is representative of the individual factors of the EMP index. The bold cells display the individual components mostly responsible for the high EMP values during these 10 periods. During March 2005, the rates of change in interest rates were the most influential value on the EMP index. However, during June 2014, both the rate-of-change in exchange rate and the rate-of-change interest rate were responsible for driving the EMP index into an extreme positive index. Fortunately, during July 2014, all components returned to stable values free of extreme pressure. Regarding values exceeding $p=0.05$, seven of the remaining eight pressure situations, the rate-of-change in exchange rate was mostly responsible. Moreover, during November 2011 and October 2015, the rate-of-change in interest rate was also responsible. Guru and Sarma (2013) also identified individual components as the most likely contributors of extreme pressure. In their study, the rates-in-change in exchange rate and interest rate were individually, and at different periods, responsible for all incidents of pressure.

\section{Extreme value theory: Hill estimate}

Quantiles computed according to the Hill estimate are presented in Table 12. Figure 22 confirms the earlier decision

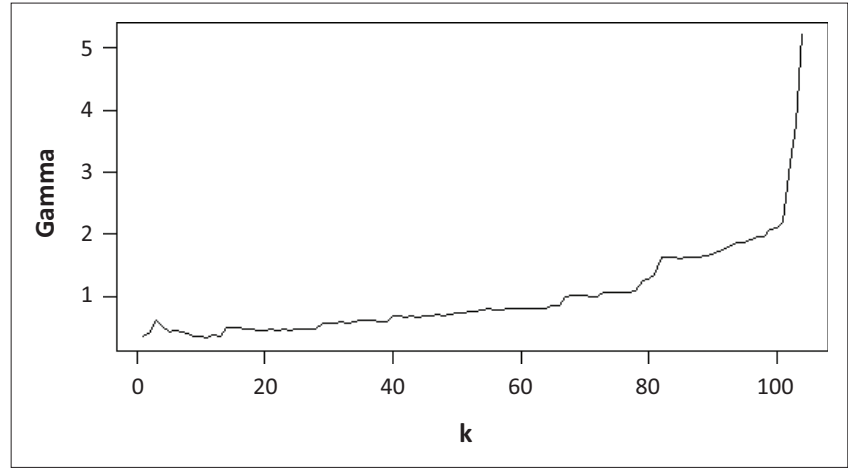

FIGURE 22: Kenya - Hill estimate to obtain cut-off between tail and central observations.

to use a threshold value of 6.50 (i.e. $K=40$ ). A parallel line to the $X$-axis can be drawn up to $k=40$. The largest 40 values were sorted from the largest to the smallest (rank ordered) and Equation 3 was applied to determine the Hill estimate (Xi [Hill]).

The Hill estimate calculated is 0.68015 .

The 100pth quantile using the Hill estimator was also calculated according to Equation 4.

When revisiting Table 12, it is certain that the GPD POT method provides a better estimate of the empirical quantiles compared to the Hill estimate. This is shown across all quantiles (0.80-0.999). There are only five quantiles where the Hill estimate provides a better index compared to the GPD POT method.

\section{Discussion}

The results of this study are unique as the EMP using EVT in Africa has never been studied as far as we are aware and contribute to the scant available research on the topic. Moreover, the study provides accurate estimated quantiles of extreme pressure and possible causes thereof. Information of this nature is important as extreme pressure could affect many economic variables, such as inflation, trade balance, unemployment, disproportionate credit growth, an increase in the current account deficit, outflow of portfolio management and flight of capital, to name a few. An EMP analysis of this kind is even more important in developing countries, such as SA and Kenya, with high rates of unemployment, negative net export positions and a deteriorating foreign exchange position. Knowing the severity of the pressure the monetary authority of the country can either intervene or allow the pressure to appreciate or depreciate the exchange rate. If intervention is implemented in periods of depreciative pressure, policymakers can raise the interest rate to attract investment opportunities or sell international reserves to meet the demand of foreign currency. The second main contribution of this article is its methodology regarding EVT, where the usefulness of the GDP POT method was compared with the Hill estimate. We are not aware of any studies that have 
compared these two techniques. The results are discussed in the order of the objectives of this study.

Both the South African and Kenyan EMP indices demonstrated stationarity (significant Augmented DickeyFuller test $[\mathrm{ADF}]$ and Phillips-Perron $[\mathrm{PP}]$ test statistics), high kurtosis (2.69 and 7.04) and heavy tails with positive $\mathrm{Xi}_{\mathrm{i}}$ estimates (0.40 and 0.17), indicating GPD from a Frechet subclass. As a result, the EMP indices of both countries were modelled using EVT. Similar positively skewed and heavytailed distributions $(X i=0.24)$ were also reflected in a study examining EMP performed in India (Guru \& Sarma 2013). Other EMP studies have also demonstrated non-Gaussian distributions with heavy tails (Heinz \& Rusinova 2015; Pozo \& Amuedo-Dorantes 2003).

Both estimation methods provided accurate estimations of EMP when studied as quantiles and compared to actually observed quantiles. However, quantiles estimated by the GPD POT method using maximum likelihood estimation (MLE) were more closely reflected to the empirical quantiles and the diagnostic plots demonstrated a good fit. Poor results were reported when the Hill estimate was used for higher percentiles (0.990; 0.995 and 0.999) when compared to empirical quantiles. Consequently, periods of extreme pressure at $p=0.99$ were not flagged and stress situations could not be identified as reported in the next two paragraphs.

Using $p=0.05$, eight periods of stress were reported for the South African data (GPD POT). At $p=0.01$, four periods of extreme stress or crisis were depicted (GPD POT). The years and months flagged were December 2001, March 2004, June 2006, June 2007, October 2008, February 2014, December 2015 and February 2016. Although a near currency crisis was elicited in January 2014 and February 2014, no periods of currency crisis were identified. The four periods of extreme pressure with $p=0.01$ were December 2001, June 2006, October 2008 and February 2014. Using the Hill estimate, the same periods of time would be selected at $p=0.05$, but at $p=0.01$ only one period of extreme pressure is flagged.

At $p=0.05,10$ periods of stress are identified for the Kenyan data (GPD POT). At $p=0.01$, two periods of extreme stress are identified between 2000 and 2017 (GPD POT). The months affected are March and May 2005, December 2007, April 2009, August 2009, November 2011, June 2012, June and December 2014 and October 2015. No periods of currency crisis were defined. The two periods of extreme pressure $(p=0.01)$ are March 2005 and June 2014. Identical episodes are flagged when the Hill estimate is used at the 95th percentile. However, at the 99th percentile, no time periods exhibit pressure situations.

For the South African data, four periods were reported to be adversely affected by the rate-of-change in exchange rate (December 2001, June 2006, October 2008 and December 2015). In three other periods (June 2007, February 2014 and February 2016), the rate-of-change in interest rates was the most responsible for driving the EMP index into an extreme positive index. In one instance only (March 2004), the rate-ofchange in reserves-to-M1 was the most likely factor for extreme pressure.

During March 2005, November 2011 and October 2015, the rate-of-change in interest rates was the most influential value on the EMP index for the Kenyan data. However, during June 2014 and October 2015, both the rate-of-change in exchange rate and the rate-of-change in interest rate were responsible for driving the EMP index into an extreme positive index. The rate-of-change in exchange rate was mostly responsible during May 2005, December 2007, April 2009, August 2009, June 2012 and December 2014. A study that also incorporated EVT on the EMP reported that the rate-of-change in exchange rate and the rate-of-change in interest rate were individually, and at different periods, responsible for most incidents of pressure (Guru \& Sarma 2013).

\section{Limitations and future studies}

This study only applied EVT on the EMP of two African countries. Although, data were obtained for a further four African countries, EMP and EVT were not studied. Further research will be conducted in subsequent countries where the gross domestic profit may be less than that of South Africa or Kenya. Also, this study should be repeated in countries where financial variables demonstrate more volatility and uncertainty for investment opportunities.

Also, in both studied papers (SA and Kenya), distributions were GPD of the Frechet subclass. Perhaps other African countries will demonstrate the Gumbel (no tail) or Weibul (thin tail) subclass distributions. It is not known whether the EMP index can be modelled successfully and accurately with these subclasses. It is recommended that future studies model the EMP index in such cases.

As the case with most studies modelling the probability of financial events, the approaches may not be applicable to verify the actual occurrence of crisis events. There is no formal definition of extreme pressure or currency crisis derived from theory. Also banking and economic organisations do not systematically identify crisis countries. In short, there is no way to grade the precision of EMP approaches.

Clearly, substantial additional future studies are needed to develop early warning systems. This should be done to determine the trend of the EMP time series and to model it in such a manner that the probability of future crisis events could be detected and predicted. In this way, researchers can be forewarned of future crisis events. Mathematical and statistical formulas can also be applied to ascertain if changes of certain magnitude, for instance, on the rate of change in interest rate would have an effect on the exchange market pressure.

Future studies should also attempt to build on research of this nature to disseminate the fundamental causal factors, development or evolution and possible contamination effect 
of currency pressure or crisis. If a country demonstrates strong exchange market depreciative pressure, a neighbouring country, or a country with whom it has strong trade relations, is likely to experience a contagion effect.

\section{Conclusion}

The main finding that emanated from this study is that EVT, specifically the GPD POT, using maximum likelihood estimation is both feasible and accurate to estimate and model the exchange market pressure of two African countries. Comparable results where the GPD POT was used to model EMP were also mirrored in a study performed in India (Guru \& Sarma 2013). Moreover, the non-parametric method known as the Hill estimate is also a feasible and useful alternative, although less accurate at higher percentiles, for both studied data sets. Reliable threshold values were selected for both countries in order to obtain accurate estimates of the shape and scale parameters. These estimates were applied in probability calculations to estimate the right tail quantiles of the EMP index series. The 95th and 99th percentiles were used to identify periods of extreme pressure and crisis successfully. The three variables of the EMP index were studied at the time of extreme pressure or crisis to identify the variables most likely to have triggered flagged events. The results of this study may help researchers, financial analysts and economists to better understand the causal factors, development or progression of EMP and contagion effect of currency pressure or crisis.

\section{Acknowledgements}

The authors appreciate the input and assistance received from Dr A. Guru and Dr M. Sarma.

\section{Competing interests}

The authors declare that they have no financial or personal relationships that may have inappropriately influenced them in writing this article.

\section{Authors' contributions}

P.H.B. was the primary researcher and responsible for data analysis and writing of the article. E.M. was the study supervisor and responsible for writing of the article. M.C. performed data analysis. I.A.M. was responsible for the study design and provision of data.

\section{Disclaimer}

The views expressed in this article are the authors' own and do not express the official position of the institution or funder.

\section{References}

Beirlant, J., Goegebeur, Y. \& Teugels, J., 2004, Statistics of extremes, John Wiley \& Sons, Chichester, West Sussex, England.

Coles, S., 2013, An introduction to the statistical modelling of extreme values, Verlag, London.

Cumperayot, P. \& Kouwenberg, R., 2013, 'Early warning systems for currency crises: A multivariate extreme value approach', Journal of International Money and Finance 36, 151-171. https://doi.org/10.1016/j.jimonfin.2013.03.008

De Macedo, J.B., Pereira, L.B. \& Reiss, A.M., 2009, 'Comparing exchange market pressure across five African countries', Open Economics Review 20(5), 645-682. https://doi.org/10.1007/s11079-008-9087-3

Eichengreen, B., Rose, A.K. \& Wyplosz, C., 1995, 'Exchange Market Mayhem: The antecedents and aftermaths of speculative attacks', Economic Policy 21, 249-312. https://doi.org/10.2307/1344591

Eichengreen, B., Rose, A.K. \& Wyplosz, C., 1994, Speculative attacks on pegged exchange rates: An empirical exploration with special reference to the European Monetary System, National Bureau of Economic Research Working Paper, pp. 4898-4905.

Embrechts, P., Kluppelberg, C. \& Mikosch, T., 2013, Modelling extremal events for insurance and finance, Verlag, Heidelberg.

Fama, E., 1965, 'The behaviour of stock market prices', Journal of Business 38, 249-312.

Fiador, V. \& Biepke, N., 2015, 'Monetary policy and exchange market pressure Evidence from sub-Saharan Africa', Applied Economics 47(37), 3921-3937. https://doi.org/10.1080/00036846.2015.1023937

Ghalanos, A., 2015, 'rugarch': Univariate GARCH models, R Package version 1.3-6.

Gilleland, E., 2016, 'extRemes': Extreme value analysis, $R$ Package version, 2.0-8.

Girton, L. \& Roper, D, 1977, 'A monetary model for exchange market pressure applied to Postwar Canadian experience', American Economic Review 67, 537-548.

Guru, A. \& Sarma, M, 2013, Exchange market pressure in India, Discussion Papers in Economics 15, pp. 22-45.

Heinz, F.F. \& Rusinova, D., 2015, An alternative view of exchange market pressure episodes in emerging Europe: An analysis using Extreme Value Theory $-A$ working paper, European Central Bank 1818, pp. 1-28.

Hill, B.M., 1975, 'A simple general approach to inference about the tail of a distribution', Annals of Statistics 3, 1163-1174. https://doi.org/10.1214/ aos/1176343247

Huisman, R., Koedijk, K.G., Kool, C.J.M. \& Palm, F., 2001, 'Tail index estimates in small samples', Journal of Business and Economics Statistics 19, 208-216. https://doi. org/10.1198/073500101316970421

Hyndman, R., O'Hara, M., Bergmeir, C., Razbash, S. \& Wang, E., 2017, 'forecast': Forecasting functions for Time Series and Linear Models, $R$ Package version 8.2.

Kaminsky, G. \& Reinhart, C.M., 1998, Leading indicators of currency crisis, International Monetary Fund staff papers 45, pp. 1-48.

Kang, S. \& Song, J., 2017, 'Parameter and quantile estimation for the generalised Pareto distribution in peaks over threshold framework', Journal of Korean Statistical Society https://doi.org/10.1016/j.jkss.2017.02.003

Koedijk, K. \& Kool, C., 1992, 'Tail estimates of East European exchange rates', Journal of Business and Economics Statistics 10, 15-29.

Mahdi, E. \& McLeod., 2017, 'Portes': Portmanteau Tests for Univariate and Multivariate Time Series, $R$ Package version 2.1-4.

McFarlane, L., 2010, Exchange Market Pressure, currency crisis and monetary policy: Evidence from Jamaica, Bank of Jamaica working paper F31, pp. 1-33.

McNeil, A.J. \& Frey, R., 2000, 'Estimation of tail related risk measures for heteroscedastic financial time series: An extreme value approach', Journal of Empirical Finance 7, 271-300.

McNeil, A.J., Frey, R. \& Embrechts, P., 2005, Quantitative risk management, Princeton University Press, Woodstock, Oxfordshire.

Pozo, S. \& Amuedo-Dorantes, C.A., 2003, 'Statistical distributions and the identification of currency crisis', Journal of International Money and Finance 22, 591-609. https://doi.org/10.1016/S0261-5606(03)00024-X

Rocco, M., 2014, 'Extreme value theory in finance: A survey', Journal of Economic Surveys 28(1), 82-108. https://doi.org/10.1111/j.1467-6419.2012.00744.x

Reynkens, T., Verbelem, R., Bardoutsos, A., Cornilly, D., Goegebeur, Y. \& Herrmann, K., 2017, 'Relns': Functions from 'Reinsurance: Actuarial and Statistical Aspects', $R$ package version, 1.0.5.

Reiss, R.D. \& Thomas, M., 2013, Statistical analysis of extreme values, Verlag, Basel.

Trapletti, A., Hornik, K. \& LeBaron, B., 2017, Tseries: Time Series Analysis and Computational Finance, $R$ Package version 0.10-42.

Wuertz, D., 2013, 'fExtremes': Rmetrics-extreme financial market data, $R$ Package version, 3010.81.

Wuertz, D., Setz, T. \& Chalabi, Y., 2014, 'fBasics': Rmetrics - Markets and basic statistics, R Package version 3011.87 